BRUNO TREVIZAN DE OLIVEIRA

\title{
ARQUITETURA DE SEGURANÇA FIM-A-FIM PARA REDES DE SENSORES SEM FIO
}

Dissertação apresentada à Escola Politécnica da Universidade de São Paulo para obtenção do Título de Mestre em Ciências. 


\section{BRUNO TREVIZAN DE OLIVEIRA}

\section{ARQUITETURA DE SEGURANÇA FIM-A-FIM PARA REDES DE SENSORES SEM FIO}

Dissertação apresentada à Escola Politécnica da Universidade de São Paulo para obtenção do Título de Mestre em Ciências.

Área de Concentração:

Sistemas Digitais

Programa de Engenharia Elétrica

Orientadora:

Profa. Dra. Cíntia Borges Margi 
Este exemplar foi revisado e alterado em relação à versão original, sob responsabilidade única do autor e com a anuência de seu orientador.

São Paulo, 31 de agosto de 2012.

Assinatura do autor

Assinatura do orientador

FICHA CATALOGRÁFICA

Oliveira, Bruno Trevizan de

Arquitetura de Segurança Fim-a-Fim para Redes de Sensores sem Fio/ B. T. Oliveira. - ed. rev. - São Paulo, 2012.

$99 \mathrm{p}$.

Dissertação (Mestrado) - Escola Politécnica da Universidade de São Paulo. Departamento de Engenharia de Computação e Sistemas Digitais.

1. Wireless 2. Sensor 3. Segurança de redes 4. Criptologia I. Universidade de São Paulo. Escola Politécnica. Departamento de Engenharia de Computação e Sistemas Digitais. II. t. 


\section{AGRADECIMENTOS}

Primeiramente, agradeço à minha orientadora Profa. Dra. Cíntia Borges Margi. Pelas oportunidades, pela amizade, por me orientar em minha formação e por sua valiosa atenção e paciência durante nossas discussões sobre a pesquisa.

Agradeço ao meu pai José Abreu de Oliveira, a todos meus familiares, e aos meus amigos Jaime M. Guedes e Joyce S. Pataro, por todas as palavras de incentivo e pelo companheirismo durante esse período difícil e conturbado da minha vida que foi o mestrado.

Também agradeço a todos meus amigos do Laboratório de Arquitetura e Redes de Computadores (LARC), em especial ao Mateus A. S. Santos e ao Geovandro C. C. F. Pereira, pelo apoio moral, pelos momentos de descontração e pelas discussões acerca da minha pesquisa.

Além disso, agradeço aos professores Dr. Paulo S. L. M. Barreto, Dr. Carlos E. Cugnasca e Dr. Routo Terada pela a atenção prestada a este trabalho e por seus valiosos comentários durante as arguições do exame de qualificação e da apresentação da dissertação de mestrado.

Por fim, agradeço à Fundação de Amparo à Pesquisa do Estado de São Paulo (FAPESP) pelo financiamento integral desde trabalho (processo FAPESP 2010/02909-8). 


\section{RESUMO}

Diversas aplicações de redes de sensores sem fio necessitam de serviços de segurança, como confidencialidade, integridade e autenticação de origem de dados. Contudo, dadas as limitações de processamento, memória e suprimento de energia dos dispositivos, os mecanismos de segurança tradicionais podem causar efeitos indesejáveis na rede, como atraso na comunicação e aumento no consumo de energia, impondo obstáculos para seu uso na tecnologia em questão. Muitas propostas de esquemas de segurança baseados em criptografia simétrica projetados especificamente para redes de sensores sem fio são encontradas na literatura. Contudo, essas soluções são focadas na segurança salto-a-salto. Tal abordagem é adequada para garantir a segurança dos enlaces deste tipo de rede, mas não garante a segurança na comunicação fim-a-fim. Neste trabalho são apresentados cenários e desafios de implementação de segurança neste tipo de rede, e a concepção, o projeto e a implementação de uma arquitetura de segurança para redes de sensores sem fio, que tem como objetivos: prover segurança na comunicação fim-a-fim; permitir a interoperabilidade entre diferentes sistemas; e possibilitar uma maior flexibilidade em relação à utilização de chaves criptográficas em diferentes cenários e topologias. Adicionalmente, a solução proposta suporta ativação e desativação de seus serviços em tempo de execução. O projeto da referida arquitetura, atuante na camada de aplicação da pilha de protocolos de rede, foi construído com base na análise das características de arquiteturas encontradas na literatura, bem como de estratégias adotadas por estas. Para a construção da implementação foram selecionados mecanismos e algoritmos criptográficos a partir da avaliação de desempenho que considerou as métricas de uso de memória, tempo de execução e consumo de energia. Como resultados são apresentados a especificação da arquitetura, a avaliação qualitativa da mesma e a avaliação de desempenho da implementação desenvolvida como prova de conceito. Além disso, é apresentada uma análise do impacto de diferentes topologias e características de disposição na tarefa de distribuição de chaves criptográficas em redes de sensores sem fio.

Palavras-chave: Redes de Sensores sem Fio. Segurança de Redes. Segurança Fim-a-Fim. Criptografia Simétrica. Código de Autenticação de Mensagem. 


\begin{abstract}
Many wireless sensor networks applications need security services, such as confidentiality, data integrity and data source authentication. On the other hand, because of device limitations, security mechanisms may affect the network energy consumption and communication delay, which impose a great challenge for practical implementation of security mechanisms in such scenario. Many solutions based on symmetric cryptography were proposed for the specific challenges of wireless sensor networks. Nevertheless, they are focused on hop-by-hop security. Such approach is suited to provide link-layer security, but it cannot guarantee end-to-end security. This work presents scenarios and challenges to implement security in wireless sensor networks, and the conception, design and implementation of a security architecture, which aims to provide: security in end-to-end communication; interoperability between different systems, and enable greater flexibility in cryptographic keys distribution in different scenarios and topologies. Additionally, the proposed solution supports on-the-fly adjustment of its security services. The architecture design, which targets the application layer of the network protocol stack, was based on the main properties of the architectures found in literature as well as adopted strategies. For the implementation, mechanisms and cryptographic algorithms were selected through the performance evaluation that considers memory usage, execution time and power consumption as metrics. The results were the architecture specification and its qualitative analysis, and the performance evaluation of the implementation developed as proof of concept. Furthermore, we present an analysis of topology and deployment impact on key distribution task.
\end{abstract}

Keywords: Wireless Sensor Networks. Network Security. End-to-end Security. Symmetric Cryptography. Message Authentication Code. 


\section{SUMÁRIO}

Lista de Abreviaturas e Siglas

\section{Lista de Ilustrações}

\section{Lista de Tabelas}

1 Introdução

1.1 Objetivos ............................ 17

1.2 Justificativa . . . . . . . . . . . . . . . . . 17

1.3 Materiais e Métodos . . . . . . . . . . . . . . . 20

1.4 Contribuições Originais e Publicações . . . . . . . . . . . . . . . . 21

1.5 Organização do Documento . . . . . . . . . . . . . 23

2 Segurança de Redes $\quad 25$

2.1 Cifração . . . . . . . . . . . . . . . . . 26

2.2 Código de Autenticação de Mensagem . . . . . . . . . . . 29

3 Segurança em Redes de Sensores sem Fio 32

3.1 Características de Redes de Sensores sem Fio . . . . . . . . . . 32

3.1.1 Conflito entre Minimizar o Consumo de Recursos e Maximizar a Segurança . . . . . . . . . . . . . 33

3.1.2 Características da Comunicação sem Fio . . . . . . . . . 34 
3.1.3 Topologia Suscetível a Ataques Físicos . . . . . . . . . 36

3.2 Arquiteturas de Segurança para Redes de Sensores sem Fio . . . . 37

3.2 .1 TinySec . . . . . . . . . . . . . . . . 38

3.2 .2 MiniSec . . . . . . . . . . . . . . . . 39

3.2 .3 ContikiSec . . . . . . . . . . . . . . . 40

3.2.4 Segurança do Padrão IEEE 802.15.4 . . . . . . . . . . . 42

3.3 Análise Comparativa de Arquiteturas de Segurança para Redes de Sensores sem Fio . . . . . . . . . . . . . . . . 43

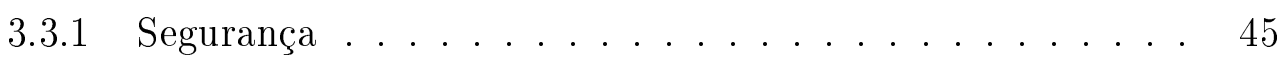

3.3 .2 Eficiência . . . . . . . . . . . . . 48

3.3.2.1 Overhead de Comunicação . . . . . . . . . . . 49

3.3.2.2 Overhead de Processamento . . . . . . . . . 51

3.3.3 Considerações sobre as arquiteturas analisadas $\ldots . . . \quad 52$

4 Análise de Abordagens de Distribuição de Chaves 54

4.1 Tipos de Distribuição de Chaves em RSSFs . . . . . . . . . . . . 54

4.1.1 Requisitos e Métricas . . . . . . . . . . . . . 55

4.1 .2 Esquemas de Pré-distribuição . . . . . . . . . . . 56

$4.1 .3 \quad$ Esquemas Arbitrados . . . . . . . . . . . . 58

4.1.4 Esquemas Auto-Regulados . . . . . . . . . . 58

4.2 Análise Comparativa . . . . . . . . . . . . . . . 61

4.2.1 Aplicações Pouco Suscetíveis a Captura de Nós . . . . . . 62 
4.2 .2 Topologia Plana . . . . . . . . . . . . . 63

4.2.3 Topologia Hierárquica . . . . . . . . . . . . . . . 64

4.2.4 Topologia Estacionária com Sorvedouro Itinerante . . . . . 65

4.3 Considerações do Capítulo . . . . . . . . . . . . . 66

$\begin{array}{lll}5 & \text { Arquitetura Proposta } & 67\end{array}$

5.1 Visão Geral . . . . . . . . . . . . . . . . . . 67

5.2 Detalhes de Especificação . . . . . . . . . . . . 69

5.3 Análise de Algoritmos Candidatos à Implementação da Arquitetura 74

5.3.1 Metodologia de Avaliação de Desempenho e Uso de Memória 75

5.3.2 Resultados da Seleção dos Algoritmos . . . . . . . . . . 77

5.4 Implementação da Arquitetura para Prova de Conceito . . . . . . 81

6 Avaliação da Arquitetura Proposta $\quad 85$

6.1 Desempenho da Implementação da Arquitetura . . . . . . . . . 85

6.2 Avaliação da Especificação . . . . . . . . . . . . . . . 88

$\begin{array}{llr}7 & \text { Considerações Finais } & 90\end{array}$

7.1 Trabalhos Futuros . . . . . . . . . . . . . . . 91

$\begin{array}{ll}\text { Referências } & 92\end{array}$

Apêndice A - Publicação Científica e Demonstração Técnica da $\begin{array}{lr}\text { Arquitetura } & 98\end{array}$ 


\section{LISTA DE ABREVIATURAS E SIGLAS}

\begin{tabular}{|c|c|}
\hline AES & Advanced Encryption Standard \\
\hline ANSI & American National Standards Institute \\
\hline $\mathrm{CBC}$ & Cipher-Block Chaining \\
\hline CBC-MAC & $C B C$ with $M A C$ \\
\hline $\mathrm{CCM}$ & Counter with $C B C-M A C$ \\
\hline $\mathrm{CDC}$ & Centro de Distribuição de Chaves \\
\hline $\mathrm{CRC}$ & Cycle Redundance Check \\
\hline DA & Dados Associados \\
\hline DES & Data Encryption Standard \\
\hline GPIB & General Purpose Interface Bus \\
\hline LFSRc & Linear Feedback Shift Register Counter \\
\hline $\mathrm{MAC}$ & Message Authentication Code \\
\hline MANETs & Multi-hop Ad Hoc Networks \\
\hline NIST & National Institute of Standards and Technology \\
\hline $\mathrm{OCB}$ & Offset CodeBook \\
\hline RAM & Random Access Memory \\
\hline RISC & Reduced Instruction Set Computer \\
\hline $\mathrm{RSA}$ & Rivest-Shamir-Adleman \\
\hline RSSFs & Redes de Sensores sem Fio \\
\hline
\end{tabular}




\section{LISTA DE ILUSTRAÇÕES}

1 Representação genérica de um sistema de cifração . . . . . . . . 27

2 Processo de autenticação utilizando um algoritmo de código de autenticação de mensagem . . . . . . . . . . . . . . 30

3 Possível leiaute de roteamento e colaboração de uma Rede de Sensores sem Fio ...................... 35

4 Ataque de repetição . . . . . . . . . . . . . . . . 36

5 Formato dos pacotes da TinySec em comparação com o pacote TinyOS padrão (KARLOF; SASTRY; WAGNER, 2004) . . . . . . 39

6 Formatos dos pacotes MiniSec em contraste com os pacotes da TinySec e do TinyOS (LUK et al., 2007) . . . . . . . . . . . 41

7 Formatos de pacotes do ContikiSec em comparação com o pacote padrão do sistema operacional Contiki (CASADO; TSIGAS, 2009) 42

8 Conjunto de configurações de segurança do padrão IEEE $802.15 .4($ IEEE, 2006) . . . . . . . . . . . 43

9 Propriedades das arquiteturas de segurança analisadas . . . . . 45

10 Nó comprometido capaz de executar ataque aos serviços de confidencialidade, autenticidade e integridade . . . . . . . . . 46

11 Taxonomia de topologias de redes de sensores sem fio . . . . . 62

12 Formato do pacote adotado para a arquitetura proposta . . . . . 70

13 Protocolo de construção do cabeçalho de configuração . . . . . . . 70 
14 Vetor de inicialização . . . . . . . . . . . . . . . . . 71

15 Exemplo de utilização de chaves simétricas de grupo . . . . . . . 73

16 Conjunto de equipamentos utilizado para análise de desempenho e exemplo de amostragem através do método de medição $\ldots$. . . 76

17 Representação gráfica do desempenho dos algoritmos de código de autenticação de mensagem . . . . . . . . . . . 78

18 Tempo de execução dos algoritmos de cifração autenticada com dados associados ....................... 81

19 Gráfico do tempo de execução das operações dos modos de funci-

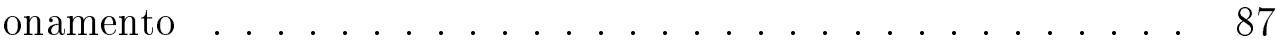

20 Gráfico do consumo de energia das operações dos modos de funci-

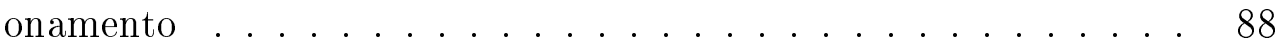

21 Leiaute da demonstração apresentada no SBRC 2012 . . . . . . . 99 


\section{LISTA DE TABELAS}

1 Especificação de hardware de algumas plataformas de sensores sem

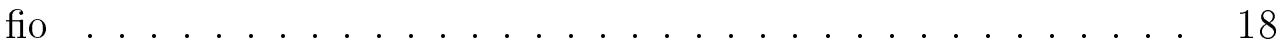

2 Dados de desempenho dos algoritmos de código de autenticação de mensagem no sensor TelosB obtidos da média de 10 amostras para cada configuração . . . . . . . . . . . . . . . . 78

3 Dados do uso de memória dos algoritmos de código de autenticação de mensagem no sensor TelosB obtidos através das ferramentas MSP430-size e MSP430-ram-usage ............ 79

4 Dados de desempenho dos algoritmos de cifração autenticada com dados associados no sensor TelosB obtidos da média de 10 amostras para cada configuração . . . . . . . . . . . . . . 80

5 Dados do uso de memória dos algoritmos de cifração autenticada com dados associados no sensor TelosB obtidos através das ferramentas MSP430-size e MSP430-ram-usage ......... 82

6 Dados de desempenho dos modos de funcionamento no sensor TelosB obtidos da média de 10 amostras para cada configuração . . 86 


\section{INTRODUÇÃO}

No início da década de 1980, a comunicação informatizada emergiu como um fenômeno econômico e cultural sem precedentes. No fim da mesma década os computadores pessoais tornam-se mais potentes e fáceis de utilizar, possibilitando a diversificação do seu uso. Desde então, o computador pessoal passou a ser uma ferramenta cada vez mais presente no cotidiano, tornando-se um dos principais instrumentos de administração e de comunicação da atualidade.

No final da década de 1990 surgiram as primeiras soluções comerciais para atender à crescente demanda por conectividade sem fio e mobilidade. Atualmente, tecnologias de redes sem fio são utilizadas em diversos dispositivos computacionais, como: computadores portáteis, videogames, telefones celulares, tocadores de áudio, entre outros. A partir do desenvolvimento dessas tecnologias e da evolução das pesquisas com semicondutores, surgiu a oportunidade de introduzir avanços significativos em diversos ramos da ciência e da atividade econômica através das Redes de Sensores sem Fio (RSSFs) (CULLER; ESTRIN; SRIVASTAVA, 2004).

RSSFs são uma valiosa tecnologia para o desenvolvimento de aplicações em diversas áreas. Gerenciamento de equipamentos e estoque, monitoramento de estruturas, monitoramento ambiental, cuidados com a saúde, controle de processos industriais, vigilância militar em campos de batalhas e sistemas de segurança comerciais são algumas entre as inúmeras aplicações emergentes para a tecnologia em questão (ZHAO; GUIBAS, 2004). 
As RSSFs são uma classe especial de redes de computadores formadas por um grande número de dispositivos computacionais de baixo custo providos de elementos de sensoriamento, e que geralmente utilizam baterias como fonte de energia. Esses dispositivos, chamados neste contexto de nós sensores, utilizam comunicação sem fio de baixa potência para interagir, o que os diferencia de uma mera coleção de sensores, possibilitando a cooperação e a coordenação entre os nós sensores ativos (HONG et al., 2007). Por se tratarem de dispositivos de baixo custo e por ser interessante que sejam de tamanho reduzido, os nós sensores frequentemente apresentam recursos limitados de processamento, memória, comunicação e suprimento de energia (CULLER; ESTRIN; SRIVASTAVA, 2004).

Existem algumas soluções comerciais que utilizam RSSFs, um exemplo é o $\bar{e}$ Ko Pro Series (MEMSIC, 2010b), que torna possível o monitoramento ambiental preciso, um importante recurso para agricultura. Contudo, ainda há poucas soluções desenvolvidas se comparado às inúmeras aplicações cogitadas para a tecnologia.

O aprimoramento da tecnologia em questão depende principalmente de dois fatores: da evolução da indústria eletrônica, permitindo o desenvolvimento de dispositivos menores, mais poderosos e baratos; e da pesquisa na área de redes de computadores e sistemas distribuídos, para tornar as RSSFs mais inteligentes, eficientes e confiáveis.

O presente trabalho se enquadra na área de pesquisa em redes de computadores e sistemas distribuídos. Tem como foco o emprego de serviços de segurança de redes em RSSFs, mais especificamente os serviços de confidencialidade, integridade, e autenticação de origem dos dados, com o objetivo de atender os requisitos de segurança apresentados por diversas aplicações da tecnologia. 


\subsection{Objetivos}

O presente trabalho tem como objetivos: investigar o estado da arte das soluções de segurança para RSSFs baseadas em criptografia, bem como as características dos dispositivos que compõem este tipo de rede relevantes à segurança, a partir de pesquisa na literatura; conceber e projetar uma arquitetura de segurança fim-a-fim para RSSFs considerando as características e as estratégias das soluções anteriores encontradas na literatura, bem como suas deficiências; e implementar e validar a referida arquitetura.

Essa arquitetura de segurança foi projetada para atuar na camada de aplicação da pilha de protocolos de rede, permitindo, além da segurança fim-a-fim na comunicação, a interoperabilidade dos serviços de segurança entre diferentes sistemas, e uma maior flexibilidade em relação a distribuição de chaves criptográficas em diversos cenários e topologias.

Ainda, a arquitetura de segurança proposta permite a ativação e a desativação de seus serviços em tempo de execução. Isto possibilita minimizar a utilização de recursos da rede, adequando o funcionamento da arquitetura às necessidades e às prioridades de segurança e de desempenho da aplicação, o que é muito útil em aplicações nas quais a sensibilidade dos dados transmitidos podem variar ao longo do tempo. Desta forma, é possível otimizar a utilização dos mecanismos de segurança, minimizando seu impacto em relação ao desempenho e ao tempo de vida da rede no que diz respeito ao suprimento de energia.

\subsection{Justificativa}

Há diversas aplicações de RSSFs nas quais os serviços de segurança podem ser um requisito desejável (acessório) ou mesmo mandatório, cada qual com necessidades de serviços diferentes. 
Em uma aplicação de monitoramento climático de uma floresta ou plantação para fins de pesquisa, por exemplo, é necessário que os dados reflitam a realidade, denotando a importância da integridade dos dados. Em outro cenário pode-se considerar que os dados da plantação monitorada são sigilosos, pois a divulgação dos mesmos poderia gerar vantagens a concorrentes, desta forma fica evidente a necessidade da confidencialidade dos dados. Se considerado que os dados climáticos da plantação podem acionar alguma ação de manutenção na mesma, como irrigação ou proteção contra algum agente natural (sol, chuva, etc.), além dos serviços de confidencialidade e integridade dos dados é necessário garantir a autenticação da origem dos dados, pois em aplicações críticas uma informação incorreta, implantada por um agente malicioso, pode levar a uma ação errada, e por consequência ocasionar algum tipo de desastre ou prejuízo.

Como discutido anteriormente neste capítulo, uma premissa das RSSFs é que seus componentes (nós sensores) são de baixo custo. Uma característica em favor da redução do custo dos dispositivos das RSSFs é a utilização de componentes de baixas capacidades, o que também favorece sua miniaturização. Sendo assim, os nós sensores possuem limitados recursos de processamento, armazenamento, comunicação, energia, além dos recursos de coleta de informações do ambiente, os sensores propriamente ditos (CULLER; ESTRIN; SRIVASTAVA, 2004).

Tabela 1: Especificação de hardware de algumas plataformas de sensores sem fio

\begin{tabular}{lcccc}
\hline Sensor sem fio & Microcontrolador & $\begin{array}{c}\text { Memória } \\
\text { de código }\end{array}$ & RAM & $\begin{array}{c}\text { Largura } \\
\text { de banda }\end{array}$ \\
\hline MICAz (MEMSIC, 2010a) & $7,3 \mathrm{MHz}$ & $128 \mathrm{KiB}$ & $4 \mathrm{KiB}$ & $250 \mathrm{~kb} / \mathrm{s}$ \\
Mica2 (MEMSIC, 2012) & $7,3 \mathrm{MHz}$ & $128 \mathrm{KiB}$ & $4 \mathrm{KiB}$ & $38.4 \mathrm{~kb} / \mathrm{s}$ \\
FireFly (NANO-RK, 2012) & $7,3 \mathrm{MHz}$ & $128 \mathrm{KiB}$ & $8 \mathrm{KiB}$ & $250 \mathrm{~kb} / \mathrm{s}$ \\
TelosB (MEMSIC, 2010c) & $8 \mathrm{MHz}$ & $48 \mathrm{KiB}$ & $10 \mathrm{KiB}$ & $250 \mathrm{~kb} / \mathrm{s}$ \\
\hline
\end{tabular}

A Tabela 1 contém algumas especificações de hardware de dispositivos de RSSFs que ilustram bem as limitações típicas dos nós sensores. O nó sensor TelosB (MEMSIC, 2010c), por exemplo, é um dispositivo que possui um microcontrolador de arquitetura Reduced Instruction Set Computer (RISC) de $8 \mathrm{MHz}$ 
de clock, com $48 \mathrm{KiB}$ de memória flash utilizada para armazenar os programas (memória de código) e $10 \mathrm{KiB}$ de memória volátil (memória de programa), ou Random Access Memory (RAM), e comunicação sem fio com taxa de transmissão de no máximo $250 \mathrm{~kb} / \mathrm{s}$. Essas limitações têm total impacto sobre os produtos finais e precisam ser consideradas no desenvolvimento de aplicações e mecanismos para essa tecnologia.

O principal desafio da área de pesquisa de segurança em RSSFs é projetar soluções que administrem bem o conflito entre minimizar consumo de recursos e maximizar a segurança, dado que as limitações dos nós sensores restringem o uso de diversos mecanismos, algoritmos e protocolos tradicionais de segurança de redes.

As operações criptográficas, utilizadas nas soluções de segurança, implicam em overhead de processamento e, por consequência, de consumo de energia. Como estas operações precisam ser executadas tanto no nó de origem quanto nos nós que precisem ler o conteúdo da mensagem, e frequentemente requerem a adição de tráfego de dados de controle, pode-se dizer que o overhead é introduzido na rede inteira, o que inevitavelmente resultará em uma rede de tempo de vida menor por conta do esgotamento do suprimento de energia. Desta forma, é importante que sejam desenvolvidas soluções de segurança especificamente para a tecnologia aqui discutida.

Para suprir os requisitos de segurança mencionados e administrar o conflito crítico com o desempenho, diversos autores propuseram arquiteturas de segurança dedicadas às RSSFs. Dentre elas se destacam: TinySec (KARLOF; SASTRY; WAGNER, 2004), MiniSec (LUK et al., 2007), ContikiSec (CASADO; TSIGAS, 2009) e a especificação de segurança do padrão IEEE 802.15.4.

Contudo, essas arquiteturas foram projetadas para atuar em camadas mais baixas da pilha de protocolos de rede, o que as atrela ou a um sistema operaci- 
onal ou a um dispositivo específico, impedido a interoperabilidade dos serviços de segurança entre diferentes sistemas. Além da questão de interoperabilidade, a utilização de uma arquitetura atuante em camadas mais baixas provê apenas a segurança salto-a-salto, acarretando em algumas implicações em relação a segurança fim-a-fim. Estas implicações são discutidas no decorrer deste trabalho.

Outro aspecto a ser considerado é a proficiência em segurança dos desenvolvedores de aplicações para RSSFs. A disponibilidade de arquiteturas de segurança, como a aqui proposta, permite o desenvolvimento de aplicações seguras exigindo menor conhecimento específico por parte do desenvolvedor.

\subsection{Materiais e Métodos}

Esta seção apresenta os métodos adotados e os materiais utilizados para o desenvolvimento deste trabalho.

A revisão da literatura foi realizada a partir de consultas em livros e em anais de conferências e periódicos especializados nas áreas de segurança de redes e de redes de sensores sem fio como: ACM SenSys, ACM IPSN, ACM Transactions on Sensor Networks e IEEE SECON, além da utilização de ferramentas que auxiliam na pesquisa em base de dados de artigos científicos, como Google Acadêmico e IEEE Xplore, para verificação do estado da arte. A partir da revisão da literatura foram selecionadas as arquiteturas de segurança para RSSFs mais relevantes. Estas são analisados e discutidas, para fins de comparação e de identificação dos mecanismos e estratégias utilizados.

A partir das características analisadas foi elaborada a especificação da arquitetura de segurança fim-a-fim, principal objeto de estudo deste trabalho. Após isso, um conjunto de algoritmos de segurança foi selecionado para a implementação da arquitetura, como prova de conceito. Por fim, foi elaborada uma análise de 
desempenho da arquitetura proposta em uma plataforma de RSSFs, verificando seu impacto, dando subsídio para discutir se os objetivos foram atingidos.

Os testes de algoritmos e da arquitetura de segurança consideraram três métricas: consumo de energia, tempo de processamento e uso de memória. Para obter essas métricas de comparação os algoritmos foram implantados em um nó sensor padrão IEEE 802.15.4 (IEEE, 2006), o TelosB (MEMSIC, 2010c), utilizando o sistema operacional para RSSFs mais citado, o TinyOS (HILL et al., 2000), um sistema de código-fonte aberto. Os dados de tempo de execução e consumo de energia foram coletado através da utilização de um multímetro digital de alta precisão em conjunto com o software LabVIEW (NATIONAL INSTRUMENTS, 2012) versão 8.6, e os dados de uso de memória através de ferramentas presentes no compilador da plataforma de teste selecionada.

\subsection{Contribuições Originais e Publicações}

A principal contribuição deste trabalho foi a especificação e a implementação da arquitetura de segurança proposta apresentada na Seção 5.2 e na Seção 5.4, respectivamente. Esta arquitetura de segurança utiliza uma abordagem distinta das demais encontradas na literatura durante o desenvolvimento deste trabalho, atuando na camada de aplicação, permitindo a segurança fim-a-fim, ideal para aplicações de RSSFs nas quais o padrão de comunicação nó sensor para sorvedouro é predominante.

Essa contribuição foi publicada no artigo de OLIVEIRA e MARGI (2012a) e deu origem a ferramenta de código aberto denominada WSN-ETESec: Endto-End Security Tool for Wireless Sensor Networks (OLIVEIRA; MARGI, 2012b). Outros detalhes sobre a referida publicação são apresentados no Apêndice A.

A segunda contribuição obtida com o desenvolvimento deste trabalho é a 
análise de distribuição de chaves contida no Capítulo 4. Na qual é apresentada uma discussão sobre o impacto da topologia e das características de disposição no processo de distribuição de chaves criptográficas simétricas em RSSFs.

Tal contribuição foi publicada em forma de resumo estendido sob o título "Topology and Deployment Impact on Key Distribution in Wireless Sensor Networks" no evento 9th European conference on Wireless Sensor Networks (EWSN 2012). A apresentação do trabalho ocorreu em Trento, na Itália, e incluiu apresentação oral em sessão técnica e apresentação de pôster.

Os resultados sobre avaliação de desempenho de algoritmos de cifração autenticada com dados associados apresentados na Seção 5.3 foram obtidos em um projeto do qual o autor deste trabalho participou em colaboração com outros pesquisadores do Laboratório de Arquitetura e Redes de Computadores da Universidade de São Paulo. Esses resultados foram publicados no artigo "Comparison of Authenticated-Encryption schemes in Wireless Sensor Networks" (SIMPLICIO et al., 2011), publicado no evento 36th IEEE Conference on Local Computer Networks (LCN 2011), que aconteceu em Bonn, Alemanha.

Esse artigo foi estendido, recebendo outras análises, bem como a avaliação de desempenho de algoritmos de código de autenticação de mensagem apresentada na Seção 5.3, gerando um novo artigo que foi submetido e está em processo de avaliação para publicação no periódico Ad Hoc Networks da editora Elsevier.

Além das publicações resultantes das contribuições originais apresentadas neste trabalho, o autor participou do desenvolvimento de outros três artigos científicos durante o mestrado, todos estes sobre o assunto segurança em RSSFs. São eles:

- "Impact of Operating Systems on Wireless Sensor Networks (Security) Applications and Testbeds" (MARGI et al., 2010), que analisa o impacto das 
diferenças entre dois sistemas operacionais, TinyOS (HILL et al., 2000) e Contiki (DUNKELS; GRONVALL; VOIGT, 2004), e de algoritmos de segurança no ciclo de vida de uma rede de sensores sem fio;

- "Implementation of Data Survival in Unattended Wireless Sensor Networks Using Cryptography" (SANTOS et al., 2010), que mostra a viabilidade de implementação de técnicas de sobrevivência de dados em RSSFs desassistidas e analisa o desempenho das operações criptográficas utilizadas;

- e "Implementation of Multivariate Quadratic Quasigroup for Wireless Sensor Network" (MAIA; BARRETO; OLIVEIRA, 2010), que avalia a viabilidade do uso de algoritmos pós-quânticos baseados em quase-grupos multivariados quadráticos em RSSFs e os compara com soluções tradicionais de criptografia assimétrica.

A participação nesses artigos foi útil ao autor para aumentar sua experiência de implementação de algoritmos de segurança em RSSFs, e para aplicar e refinar o método de teste e análise de desempenho utilizados neste trabalho.

\subsection{Organização do Documento}

O presente documento está organizado em sete capítulos (incluindo este capítulo de introdução), uma lista de referências utilizadas ao longo do texto e um apêndice no qual são apresentados detalhes sobre a publicação científica e a apresentação da principal contribuição deste trabalho.

O Capítulo 2 apresenta os conceitos de segurança de redes e os mecanismos relevantes a este trabalho. No Capítulo 3 discute-se os requisitos de segurança de RSSFs, e são apresentados a revisão das arquiteturas de segurança para RSSFs encontradas na literatura e um estudo comparativo destas. 
No Capítulo 4 é apresentada uma discussão sobre o impacto das topologias de RSSFs e das características de disposição no processo de distribuição de chaves criptográficas simétricas. A especificação da arquitetura proposta, bem como os detalhes de sua implementação são apresentados no Capítulo 5, e no subsequente Capítulo 6 são apresentados e analisados os resultados obtidos neste trabalho, incluindo a avaliação qualitativa da especificação e a avaliação de desempenho da implementação da arquitetura proposta.

Por fim, as considerações finais e indicações de trabalhos futuros são apresentadas no Capítulo 7. 


\section{SEGURANÇA DE REDES}

A introdução de sistemas distribuídos e o uso de redes e recursos de comunicação para transmissão de dados entre computadores foram mudanças que afetaram fortemente a segurança da informação, reforçando então a necessidade do desenvolvimento de medidas de segurança de redes para proteger os dados durante a sua transmissão. Segurança de redes consiste em um conjunto de medidas com o objetivo de desencorajar, impedir, detectar e corrigir violações de segurança que envolva transmissão de informação (STALLINGS, 2008).

As medidas de segurança de redes são colocadas em prática através de serviços de segurança, que são classificados por Stallings (2008) em cinco categorias:

- autenticação - garantia de que a entidade com a qual se comunica é realmente aquela que afirma ser;

- integridade - garantia de que os dados recebidos não sofreram alterações durante sua transmissão;

- confidencialidade - garantia de que as mensagens trocadas serão compreendidas somente pelos usuários autorizados;

- controle de acesso - impedimento do uso não autorizado de um recurso;

- irretratabilidade - garantia de que nenhuma entidade (remetente ou destinatário) envolvida em troca de determinada mensagem possa negar sua transmissão, recepção ou posse. 
Os serviços de segurança, por sua vez, são providos por um ou mais mecanismos de segurança. Dentre os mecanismos de segurança mais importantes dentro do escopo deste trabalho pode-se destacar: a cifração, que garante a confidencialidade dos dados; e o código de autenticação de mensagem, mais conhecido como $M A C^{1}$, que garante a integridade e autenticação de origem dos dados.

O serviço de irretratabilidade não é discutido neste trabalho, pois este não se aplica ao contexto das RSSFs, dado que os participantes da rede são dispositivos, e estes não refutam transmissão, recepção ou posse de mensagens. Já o serviço de controle de acesso transcende o escopo deste trabalho, pois a implementação deste em RSSFs está fortemente relacionada a mecanismos físicos de prevenção a violações dos dispositivos.

Na Seção 2.1 é apresentado o mecanismo de cifração e na subsequente Seção 2.2 é apresentado o mecanismo de código de autenticação de mensagem.

\subsection{Cifração}

Cifração é a prática de utilizar algoritmos matemáticos para transformar dados em um formato que não seja prontamente decifrável, ou seja, gerar um texto cifrado a partir de um texto claro, com o objetivo de torná-lo incompreensível a entidades não autorizadas. A transformação para um texto cifrado e a subsequente recuperação dos dados dependem de um algoritmo e de zero ou mais chaves criptográficas (STALLINGS, 2008). Neste contexto, uma chave criptográfica é um parâmetro de entrada que especifica a transformação do texto puro em texto cifrado, ou vice-versa, para dado algoritmo de criptografia.

De uma forma genérica, a cifração é uma função $E$ que recebe como parâmetros uma chave criptográfica de cifração $K_{e}$ e um texto claro $P$, gerando como re-

\footnotetext{
${ }^{1}$ Termo vindo do inglês message authentication code.
} 
sultado um texto cifrado $C$, definido através da seguinte expressão: $C=E\left(K_{e}, P\right)$. Para que um texto cifrado $C$ retorne a sua forma original $P$, o texto claro deve ser recuperado pela expressão: $P=D\left(K_{d}, C\right)$, onde $D$ é a função de decifração e $K_{d}$ é a chave criptográfica para decifração (AMARO, 2007) . A Figura 1 ilustra esta generalização.

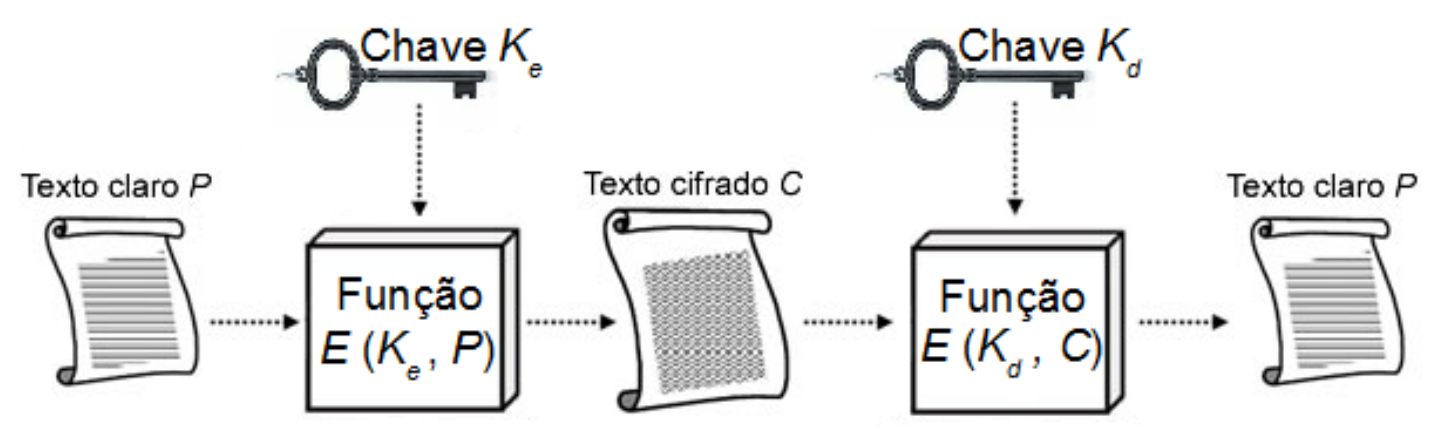

Figura 1: Representação genérica de um sistema de cifração

O número de chaves criptográficas é um dos aspectos mais importante dos sistemas criptográficos. Um sistema criptográfico no qual o emissor e o receptor utilizam uma mesma chave $\left(K_{e}=K_{d}\right)$ é classificado como criptografia simétrica. Já um sistema no qual o emissor e o receptor utilizam chaves diferentes $\left(K_{e} \neq\right.$ $K_{d}$ ) é classificado como criptografia assimétrica (AMARO, 2007).

As chaves criptográficas utilizadas em um sistema de criptografia assimétrica são conhecidas como chave pública e chave privada. A chave pública pode ser distribuída arbitrariamente, podendo qualquer entidade conhecê-la sem que a segurança seja comprometida, enquanto a chave privada deve ser mantida em segredo por parte de seu proprietário.

A adoção de um esquema de segurança baseado em criptografia simétrica requer a execução de uma tarefa que pode ser de extrema complexidade dependendo do cenário de aplicação. Para estabelecer uma comunicação segura utilizando criptografia simétrica, primeiramente um dos envolvidos deve compartilhar uma chave criptográfica simétrica com o outro envolvido, seu interlocutor, processo denominado "distribuição de chaves criptográficas". Como a chave simétrica é 
o principal elemento de segurança para a função criptográfica, é necessário que esta seja compartilhada através de um canal seguro, o que pode ser um grande desafio, dado que o que se busca com a utilização da criptografia simétrica é o estabelecimento de um canal seguro, que comumente não está disponível a priori.

Outro problema relacionado à distribuição de chaves criptográficas simétricas é a proporção de crescimento do número de distribuições necessárias para o estabelecimento de canais seguros em relação ao número de usuários de um sistema. Em um esquema de criptografia simétrica no qual há $n$ usuários envolvidos, se faz necessário distribuir $(n(n-1)) / 2$ chaves criptográficas simétricas por um meio seguro para garantir a confidencialidade entre os usuários do sistema, ou seja, garantir que nenhum usuário tenha acesso a mensagens trocadas por qualquer par de usuários que não o inclua.

Por outro lado, a criptografia assimétrica minimiza o problema de distribuição de chaves com o uso de um par de chaves criptográficas para cada entidade, composto por uma chave pública e uma chave privada, dado que a chave pública pode ser distribuída por um canal inseguro. Contudo, é fato conhecido que os algoritmos de criptografia assimétrica apresentam desempenho bem inferior àqueles apresentados pelos algoritmos de criptografia simétrica. Simplicio (2008) apresenta um exemplo que envolve dois algoritmos de criptografia bastante populares, RSA (RIVEST; SHAMIR; ADLEMAN, 1978), um algoritmo de criptografia assimétrica, e o Data Encryption Standard (DES) (FIPS, 1977), um algoritmo criptografia simétrica, no qual é possível observar que a execução do DES é de 100 a 1000 vezes mais rápido que a execução do RSA.

Dado que os algoritmos de criptografia simétrica apresentam melhor desempenho, pode-se concluir que eles são mais apropriados para a cifração de grandes volumes de informação. Por outro lado, os algoritmos de criptografia assimétrica geram um canal seguro a partir do uso de um canal inseguro, o que os 
tornam adequados para a distribuição de chaves criptográficas simétricas. Desta forma, pode-se combinar as duas categorias de algoritmos, utilizando criptografia simétrica para tratar grandes volumes de informação e criptografia assimétrica para distribuir as chaves criptográficas simétricas. Por conseguir resolver elegantemente os problemas pertinentes às questões técnicas de cada método, esta combinação tornou-se um padrão utilizado em diversos cenários (AMARO, 2007).

\subsection{Código de Autenticação de Mensagem}

Um mecanismo de código de autenticação de mensagem é uma técnica criptográfica que a partir de uma mensagem de comprimento variado e de uma chave criptográfica simétrica gera um pequeno bloco de tamanho fixo, que é o código de autenticação de mensagem (ou MAC) (STAlLINGS, 2008). Para facilitar a identificação dos componentes do código de autenticação no texto, o mecanismo será referenciado pelo termo "código de autenticação de mensagem" e o pequeno bloco de texto de tamanho fixo de "código autenticador".

O código de autenticação de mensagem é basicamente uma técnica de soma de verificação ${ }^{2}$ criptográfica, que gera o código autenticador a partir do seguinte modelo: $t=C(K, M)$, onde $t$ é o código autenticador, $M$ é a mensagem de comprimento variável, $K$ é a chave criptográfica simétrica compartilhada entre o emissor e o receptor, e $C(K, M)$ é função de geração do código autenticador. Essa é uma função de muitos-para-um, ou seja, um mesmo código autenticador pode ser gerado a partir de muitas mensagens, mas é difícil encontrar diversas mensagens que gerem o mesmo código autenticador, e esta complexidade é proporcional ao comprimento do código autenticado (em bits), que por sua vez, garante o serviço de integridade dos dados.

A autenticação de origem dos dados é garantida da mesma forma que a con-

\footnotetext{
${ }^{2}$ Mais conhecida pelo termo em inglês checksum.
} 
fidencialidade na criptografia simétrica, considerando que só um par de usuários conhece a chave criptográfica simétrica $K$, então o destinatário da mensagem tem a garantia que somente o remetente esperado pode gerar o código autenticador corretamente.

No processo do mecanismo de código de autenticação de mensagem o código autenticador gerado deve ser enviado em anexo à mensagem que pretende-se garantir a integridade e a autenticação de origem dos dados. Então, um destinatário de posse da chave criptográfica simétrica compartilhada a priori, ao receber a mensagem, gera seu próprio código autenticador e o compara com o código recebido.

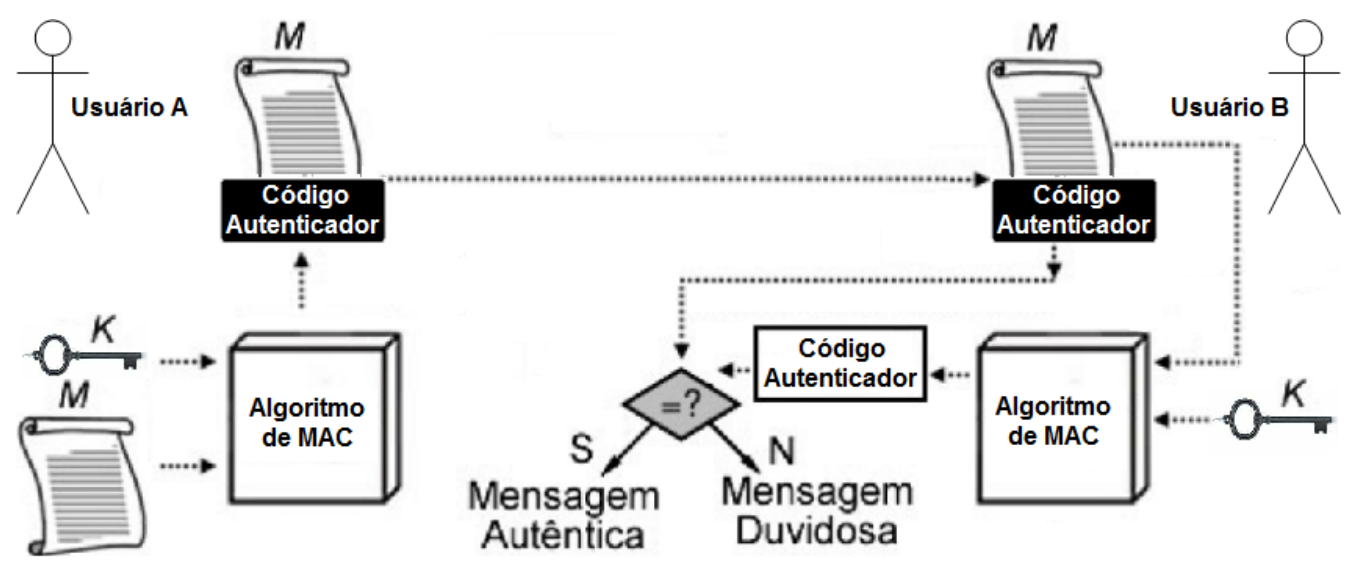

Figura 2: Processo de autenticação utilizando um algoritmo de código de autenticação de mensagem

A Figura 2 ilustra um exemplo no qual a entidade Usuário A gera um código autenticador (em preto), a partir da mensagem $M$ e da chave criptográfica simétrica $K$. Ao receber as mensagens, a entidade Usuário $B$ gera seu próprio código autenticador (em branco) a partir do mesmo processo, utilizando a mesma chave $K$, e os compara. Caso os dois códigos, o recebido e o calculado, sejam iguais, Usuário $B$ tem certeza de que a mensagem foi enviada por Usuário $A$ e que não sofreu alterações durante seu percurso, do contrário Usuário $B$ conclui que se trata de uma mensagem falsa ou alterada. Desta forma, é possível garantir que a mensagem não foi modificada durante sua transmissão, dado que a mensagem 
é uma das entradas do mecanismo, bem como reconhecer sua origem de acordo com a posse da chave criptográfica.

Um mecanismo de código de autenticação de mensagem pode ser combinada com a cifração para garantir confidencialidade, autenticação de origem e integridade dos dados, inclusive pode-se compartilhar a mesma chave criptográfica entre os dois mecanismos. A posição de cálculo do código autenticador em relação à cifração é variável, pode-se calculá-lo antes ou depois, contanto que os dois lados da comunicação saibam desta ordem. Um algoritmo de código de autenticação de mensagem, em seu estado puro, é utilizado principalmente quando somente a autenticação de origem e integridade são necessárias, ou quando a autenticação precisa persistir por mais tempo do que a confidencialidade. 


\section{SEGURANÇA EM REDES DE SENSORES SEM FIO}

Neste capítulo discute-se as características de RSSFs e seus requisitos de segurança, e são apresentados a revisão das arquiteturas de segurança para RSSFs encontradas na literatura e um estudo comparativo destas.

\subsection{Características de Redes de Sensores sem Fio}

As RSSFs possuem características que as diferenciam das redes de computadores tradicionais, e essas características têm impacto sobre os requisitos de segurança de redes, o que torna os esquemas de segurança de rede tradicionais inadequados para as RSSFs.

A densidade da rede é um fator importante para as RSSFs por duas principais características: a baixa potência de comunicação, por contra da necessidade de economia de energia, e consequentemente menor alcance do sinal de rádio; e os requisitos de precisão do sensoriamento apresentados frequentemente por diversas aplicações. Nesse contexto, é importante que os nós sensores sejam de baixo custo, facilitando sua utilização em larga escala, dado que o alto custo dos dispositivos poderia inviabilizar muitas aplicações.

Como discutido previamente, no Capítulo 1, uma característica em favor da redução do custo dos dispositivos das RSSFs é a utilização de componentes de baixas capacidades. Contudo, essa característica gera o principal desafio para 
implementação de segurança em RSSFs, administrar conflito entre minimizar o consumo de recursos e maximizar a segurança. Além deste, foram identificados outros dois em relação à segurança: as características da comunicação sem fio e a topologia suscetível a ataques ao enlace. A seguir é apresentada uma discussão sobre cada um desses desafios.

\subsubsection{Conflito entre Minimizar o Consumo de Recursos e Maximizar a Segurança}

Os nós sensores normalmente utilizam baterias como fonte de energia e, portanto, têm acesso a um suprimento limitado de energia. Dado que muitas vezes a substituição da bateria do nó sensor é complexa após sua implantação no local de sensoreamento, o esgotamento da energia da bateria define o fim do ciclo vida de um nó sensor, e por sua vez, o tempo de vida da rede como um todo. Desta forma, é importante que as aplicações e os mecanismos para RSSFs sejam projetados considerando a economia de energia.

Os componentes de uma rede de sensores sem fio possuem memória limitada, o que torna o uso deste recurso uma métrica importante a ser considerada no projeto e na avaliação da solução de segurança para RSSFs.

No que diz respeito a memória de código, onde são armazenadas as operações criptográficas e os procedimentos de execução, os nós sensores geralmente são providos de recursos na ordem de grandeza de KiB, como o MICAz (MEMSIC, 2010a) com $128 \mathrm{KiB}$ e o TelosB (MEMSIC, 2010c) com 48 KiB. Contudo, as soluções tradicionais de criptografia são muito grandes para serem utilizadas neste tipo de dispositivos. A ferramenta TrueCrypt on-the-fly encryption (TrueCrypt Foundation, 2012), por exemplo, ocupa cerca de 3.3 MiB de memória de código. Assim, é importante que os esquemas de segurança para RSSFs ocupem pouco espaço de memória de código. 
A memória volátil (ou RAM), utilizada pelas operações criptográficas para armazenar variáveis e resultados intermediários de seus cálculos, é ainda mais limitada, 4 KiB para o MICAz e $10 \mathrm{KiB}$ para o TelosB. Desta forma, é necessário que os algoritmos e suas implementações sejam projetados cuidadosamente em relação a utilização deste recurso.

Os microcontroladores presentes nos sensores sem fio são de baixo poder de processamento, da ordem de grandeza de poucos $\mathrm{MHz}$, como mostrado na Tabela 1, o que implica na necessidade de adotação de algoritmos que demandem pouco processamento, dado que um grande overhead de processamento implica em um maior atraso no tempo de resposta dos dispositivos, e no aumento do consumo de energia.

\subsubsection{Características da Comunicação sem Fio}

Diferente das redes cabeadas, as redes sem fio não possuem proteção física ao enlace, o que as torna mais vulneráveis a ataques como monitoramento do canal por partes não autorizadas e a geração de interferência, possibilitando o comprometimento dos dados. Assim, mecanismos de segurança são essenciais para prover integridade, autenticação e confidencialidade dos dados, além da qualidade e continuidade do serviço, o que os tornam requisitos críticos para a proteção de suas funcionalidades básicas (XIAO; SHEN; DU, 2006). As RSSFs, que são um tipo específico de rede sem fio, possuem algumas outras características agravantes para a segurança.

As redes locais sem fio convencionais, padrão IEEE 802.11 (IEEE, 1997), utilizadas na maioria dos computadores pessoais, comumente são configuradas no modo conhecido como infraestrutura. Trata-se de um modo que utiliza topologia fixa na qual os dispositivos participantes são conectados diretamente a um ponto de acesso, comumente interligado a uma rede cabeada, que coordena a rede 
inteira e provê serviços de acesso, funcionando como uma estação rádio base.

As RSSFs podem ser entendidas como uma classe especial de redes ad hoc de múltiplos saltos (MANETs - multi-hop ad hoc networks), sendo que ambas possuem arquitetura flexível nas quais os elementos utilizam canais de comunicação sem fio para estabelecer uma comunicação diretamente entre si, ou seja, não há uma topologia fixa predeterminada (MARGI, 2006). As MANETs suportam recursos computacionais nos quais os elementos executam diferentes tarefas, dentre as quais incluem principalmente o roteamento e o repasse de mensagens.

Frequentemente, as RSSFs trabalham de forma cooperativa com o objetivo de entregar os dados coletados pelos nós sensores para um nó central, chamada neste contexto de nó sorvedouro, para serem processados pela aplicação. A Figura 3 apresenta um exemplo de configuração para uma Rede de Sensores sem Fio, ilustrando a tarefa de encaminhamento de dados coletados na rede para o nó sorvedouro conectada à aplicação.
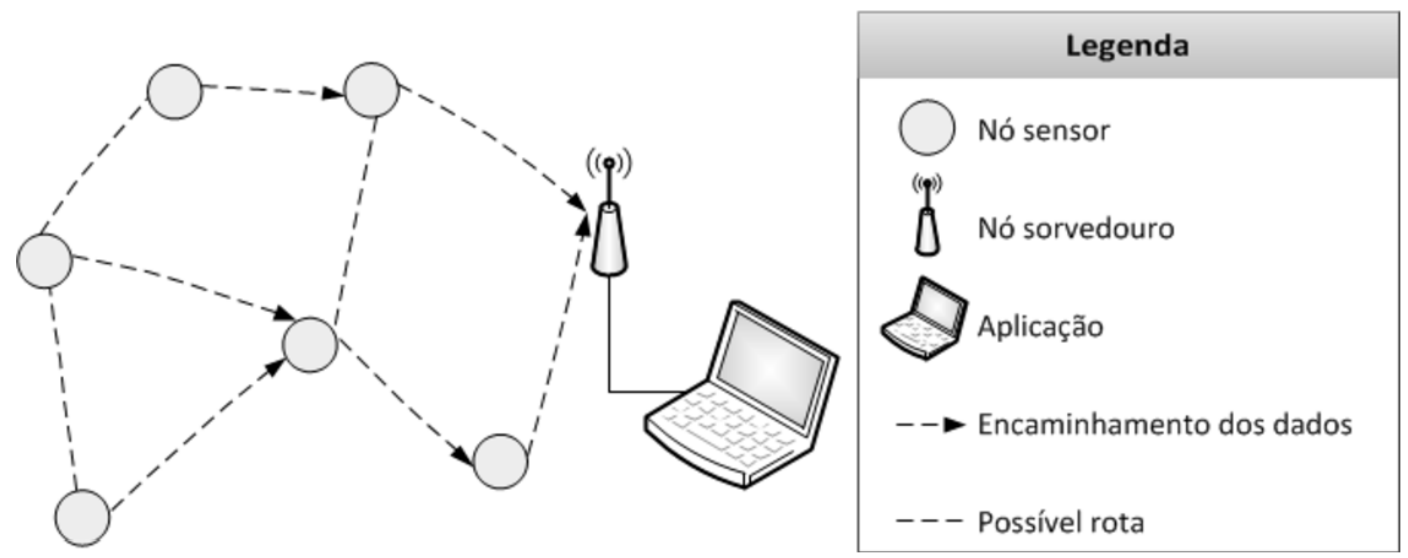

Figura 3: Possível leiaute de roteamento e colaboração de uma Rede de Sensores sem Fio

Além dos serviços de segurança de confidencialidade, integridade e autenticação de origem dos dados, também é importante adicionar proteção contra ataques de repetição, para garantir que e nenhuma entidade mal intencionada está replicando dados antigos. A Figura 4 exemplifica um ataque de repetição, no qual 
um nó malicioso executa uma escuta indevida aos dados transmitidos pelo nó número 4, e replica estes dados, transmitindo-os ao nó número 5 em um momento oportuno de acordo com sua estratégia de ataque.

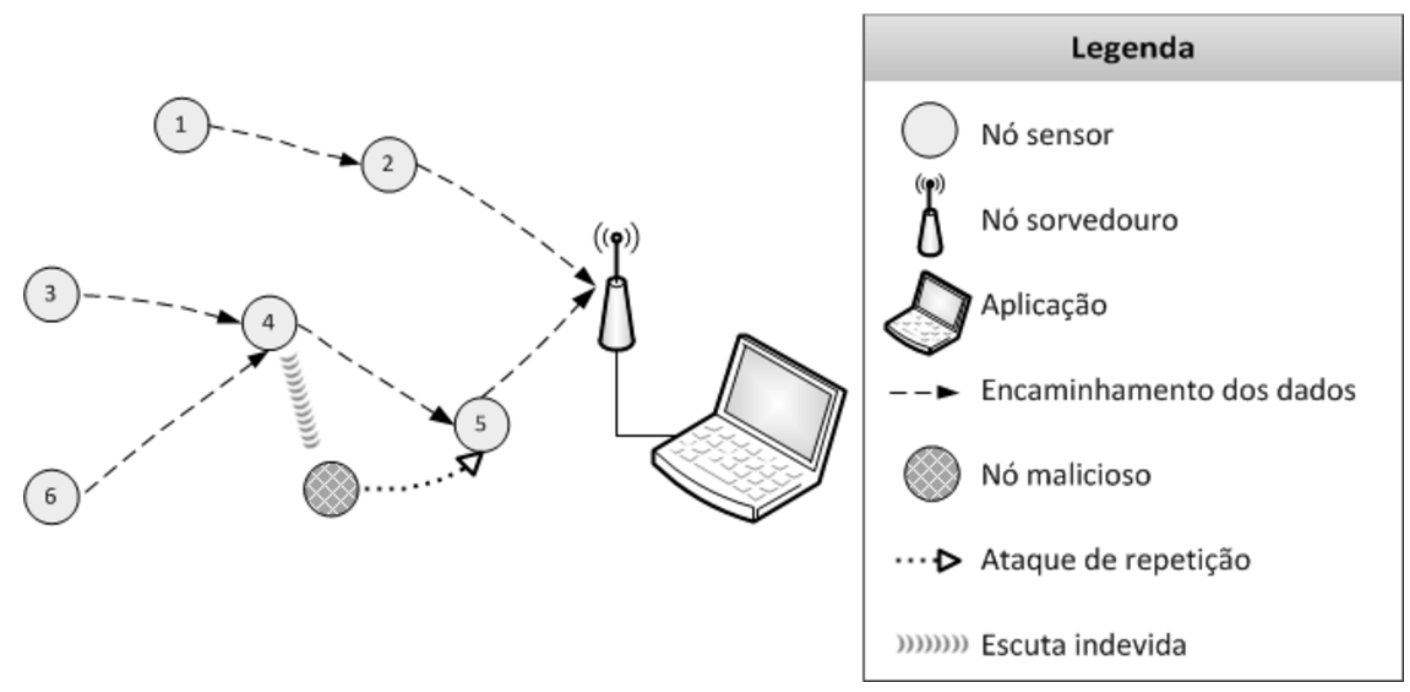

Figura 4: Ataque de repetição

Dado que a comunicação costuma ser a tarefa de uma rede de sensores sem fio que mais consome energia, aproximadamente 13 vezes mais que a tarefa de processamento para o nó sensor TelosB (MEMSIC, 2010c), o ataque de repetição também pode ser utilizado pelo adversário para provocar a aceleração do esgotamento do suprimento de energia em parte da rede, provocando o particionamento da mesma, ou na rede inteira, encurtando seu tempo vida. O esgotamento do suprimento de energia também pode ser acelerado pela injeção de dados falsos na rede.

\subsubsection{Topologia Suscetível a Ataques Físicos}

Como podem ser móveis ou permanecerem em locais não monitorados, ou sem proteção física, os nós sensores são vulneráveis a ataques físicos. Assim, uma entidade mal intencionada pode sequestrar um nó da rede impedindo que o mesmo execute suas tarefas de coleta, roteamento e repasse de dados, ou pode substituir um nó da rede por um nó falso para obter informações ou injetar dados 
falsos na rede.

Outro ataque possível é o captura do nó com o objetivo de extrair informações armazenadas, para obter autenticação ou chaves criptográficas, o sucesso deste ataque é denominado comprometimento de nó. Obviamente os algoritmos criptográficos e as arquiteturas de segurança não protegem o nós sensores contra captura ou dano, o que pode ser feito através de capas protetoras, elevando o custo monetário dos dispositivos. Contudo, os algoritmos e as arquiteturas de segurança podem minimizar os efeitos dos ataques físicos, evitando que nós comprometidos prejudiquem o funcionamento da rede como um todo. Quando um esquema de segurança para RSSFs possui a capacidade de minimizar o impacto do comprometimento de nós, dize-se que este esquema possui resiliência ao comprometimento de nós.

\subsection{Arquiteturas de Segurança para Redes de Sensores sem Fio}

Nos últimos anos diversos autores propuseram arquiteturas de segurança especificamente para RSSFs. Algumas dessas propostas foram projetadas e implementadas, recebendo assim considerável atenção na área de pesquisa em questão. Dentre elas se destacam: TinySec (KARLOF; SASTRY; WAGNER, 2004), MiniSec (LUK et al., 2007), ContikiSec (CASADO; TSIGAS, 2009) e a especificação de segurança do padrão IEEE 802.15.4 (IEEE, 2006). Essas arquiteturas são descritas na seção seguinte.

Esta seção apresenta a descrição de arquiteturas de segurança para RSSFs, listando os algoritmos que estas utilizam, identificando estratégias adotadas por elas e a quantidade de dados de controle adicionados para a transmissão, bem como a descrição dos formatos de pacotes adotados por cada uma delas. 


\subsubsection{TinySec}

A TinySec (KARLOF; SASTRY; WAGNER, 2004) foi uma das primeiras arquiteturas projetadas para RSSFs, e a primeira efetivamente implementada. Esta arquitetura foi pensada para atuar junto à camada de enlace do TinyOS (HILL et al., 2000) e prover os serviços de confidencialidade, integridade de dados e autenticação de origem.

A TinySec dispõe de dois modos de funcionamento: TinySec-Auth, para autenticação de origem e integridade de dados; e TinySec-AE, para cifração autenticada, ou seja, mensagens cifradas e autenticadas, o que também garante sua integridade. Cada um destes modos de funcionamento possui um formato de pacote específico.

No modo TinySec-AE, a carga útil é de até 29 bytes, na qual a cifração atua, e o cabeçalho do pacote é de 8 bytes (2 bytes de endereço de destino, 1 bytes de controle do Active Message, 1 byte de sinalizador de tamanho de pacote, 2 bytes de endereço de origem e 2 bytes de contador), sendo o pacote inteiro autenticado, e o cabeçalho utilizado como vetor de inicialização (mais conhecido como initialization vector) para garantir a segurança semântica (MENEZES; OORSCHOT; VANSTONE, 1997).

No modo TinySec-Auth, o pacote inteiro (dados e cabeçalho) é autenticado, sendo a carga útil também de até 29 bytes, mas o cabeçalho do pacote é de 4 bytes ( 2 bytes de endereço de destino, 1 bytes de controle do Active Message, 1 byte de sinalizador de tamanho do pacote). A Figura 5 ilustra estas configurações de pacotes em comparação com o pacote padrão do TinyOS, a parte hachurada indica os dados que são autenticados pelo mecanismo de MAC, e a parte escurecida indica os dados protegidos pela cifração.

Ambos os formatos de pacotes possuem 4 bytes reservados para o código 


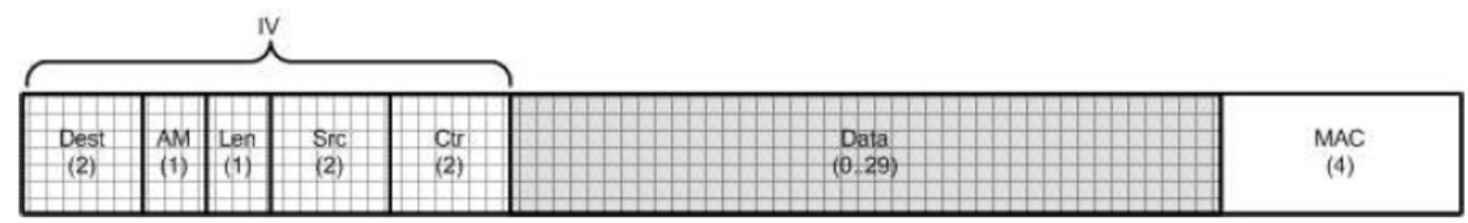

(a) Formato do pacote TinySec-AE

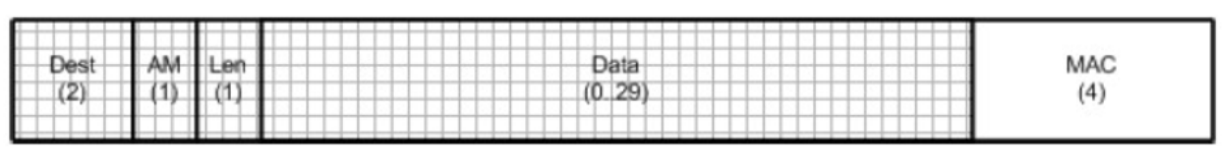

(b) Formato do pacote TinySec-Auth

\begin{tabular}{|c|c|c|c|c|c|}
\hline $\begin{array}{l}\text { Dest } \\
\text { (2) }\end{array}$ & $\begin{array}{l}\text { AM } \\
\text { (1) }\end{array}$ & $\begin{array}{l}\text { Len } \\
\text { (1) }\end{array}$ & $\begin{array}{c}\text { Grp } \\
\text { (1) }\end{array}$ & $\begin{array}{c}\text { Data } \\
(0.29)\end{array}$ & $\begin{array}{l}\text { CRC } \\
\text { (2) }\end{array}$ \\
\hline
\end{tabular}

(c) Formato do pacote TinyOS

Figura 5: Formato dos pacotes da TinySec em comparação com o pacote TinyOS padrão (KARLOF; SASTRY; WAGNER, 2004)

autenticador (ou MAC). Em "troca" disto o campo Cycle Redundance Check (CRC) do formato original do TinyOS é eliminado, tendo em vista que o código de autenticação de mensagem já provê a integridade dos dados. Com relação ao overhead de dados a serem transmitidos, a TinySec adiciona 1 byte para o modo TinySec-Auth e 5 bytes para o modo TinySec-AE. Esta arquitetura não permite a utilização de mecanismo de somente cifração.

Para prover os serviços de segurança, a arquitetura utiliza a cifra de bloco Skipjack (NSA, 1998) por padrão, o CBC-MAC (NIST, 2005) como algoritmo de código de autenticação de mensagem e o CBC-ciphertext stealing (MENEZES; OORSCHOT; VANSTONE, 1997) como modo de operação de cifra de bloco.

\subsubsection{MiniSec}

Os autores do MiniSec (LUK et al., 2007) o definem como uma arquitetura de camada de rede segura para RSSF, porém ao examiná-lo é fácil notar que ele também lida com dados da camada de enlace. Um dos objetivos dessa arquitetura 
é resolver alguns pontos fracos da TinySec, sendo sua abordagem muito parecida com este. A principal mudança de mecanismos em relação à TinySec é a troca de utilização de um modo de operação de cifra de bloco por um esquema de cifração autenticada com dados associados, ou authenticated-encryption with associateddata, o Offset CodeBook (OCB) (KROveTZ; ROGAWAY, 2005).

Em relação ao formato de pacotes, representado graficamente na Figura 6, o MiniSec introduz apenas 3 bytes de overhead para transmissão. Sua abordagem elimina o campo contador (CTR) presente na TinySec para compor o vetor de inicialização (VI), utilizando somente alguns bits do campo tamanho (LEN) e destino (DST) como parte do VI.

O MiniSec também adiciona proteção contra ataques de repetição, utilizando mecanismos de sincronização e estruturas de dados para armazenar contadores de mensagens. Estes mecanismos também contribuiriam para eliminar o campo contador (CTR) do pacote de transmissão de dados, pois os contadores para sincronização são utilizados como parte do VI complementando o mesmo.

No que diz respeito aos modos de funcionamento, o MiniSec apresenta uma limitação nas opções de escolha dos serviços de segurança. A arquitetura provê apenas o modo de funcionamento de cifração autenticada, ou seja, não é possível desativar nenhum dos serviços de segurança.

\subsubsection{ContikiSec}

A ContikiSec (CASADO; TSIGAS, 2009) é a proposta de arquitetura de segurança para camada de enlace do sistema operacional Contiki (DUNKELS; GRONVALL; VOIGT, 2004). Basicamente, ela foi projetada levando em consideração as lições aprendidas com a TinySec e MiniSec.

A arquitetura provê flexibilidade na escolha dos serviços de segurança, de 


\begin{tabular}{|c|c|c|c|c|c|c|c|c|}
\hline 1 & 2 & 1 & 2 & 2 & 1 & 1 & $0 \ldots .28$ & 2 \\
\hline Len & FCF & DSN & DstPAN & DstAddr & AM & Grp & Data & CRC \\
\hline
\end{tabular}

(a) TinyOS

\begin{tabular}{|c|c|c|c|c|c|c|c|c|c|}
\hline 1 & 2 & 1 & 2 & 2 & 1 & 2 & 2 & $0 \ldots .28$ & 4 \\
\hline Len & FCF & DSN DstPAN & DstAddr & AM SrCAddr & Ctr & Enc Dta & MIC \\
\hline
\end{tabular}

(b) TinySec-AE

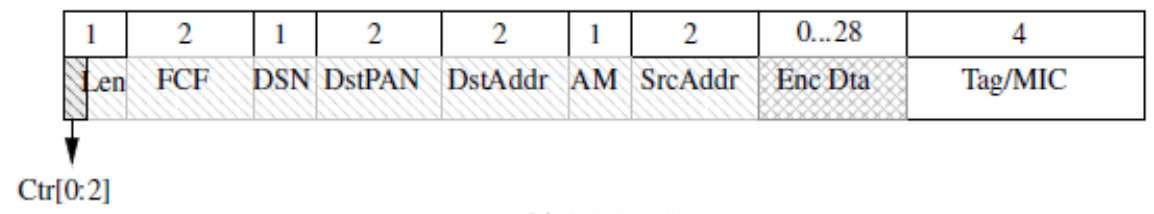

(c) MiniSec-U

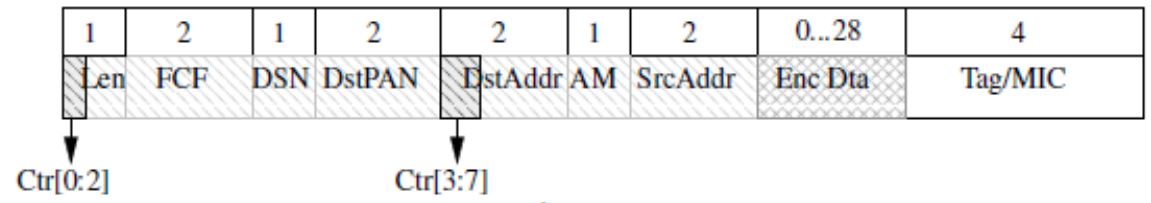

(d) MiniSec-B

Figura 6: Formatos dos pacotes MiniSec em contraste com os pacotes da TinySec e do TinyOS (LUK et al., 2007)

forma que é possível selecionar um entre os seguintes modos: ContikiSec-Auth, que provê autenticação de origem e integridade dos dados; ContikiSec-Enc, que provê confidencialidade dos dados; e ContikiSec-AE, que provê autenticação de origem, integridade e confidencialidade dos dados.

A seleção do modo de funcionamento impacta diretamente na quantidade de dados a ser adicionada aos pacotes: ao utilizar o serviço de confidencialidade são adicionados 2 bytes relativos ao VI, e ao utilizar o serviço de autenticação são adicionados 4 bytes referentes ao MAC e removendo 2 bytes de CRC, ou seja, com modo de funcionamento de cifração autenticada a arquitetura adiciona 4 bytes ao pacote. A Figura 7 apresenta os formatos de pacotes do ContikiSec em comparação com o formato do pacote padrão do Contiki.

Os algoritmos utilizados pela arquitetura são: AES-128 (DAEMEN; RIJMEN, 2000) como cifra de bloco; CBC-MAC (NIST, 2005) como código de autenticação de mensagem para o modo ContikiSec-Auth, CBC-ciphertext stealing (MENEZES; 
OORSCHOT; VANSTONE, 1997) para cifração do modo ContikiSec-Enc; e OCB para cifração autenticada do modo ContikiSec-AE.

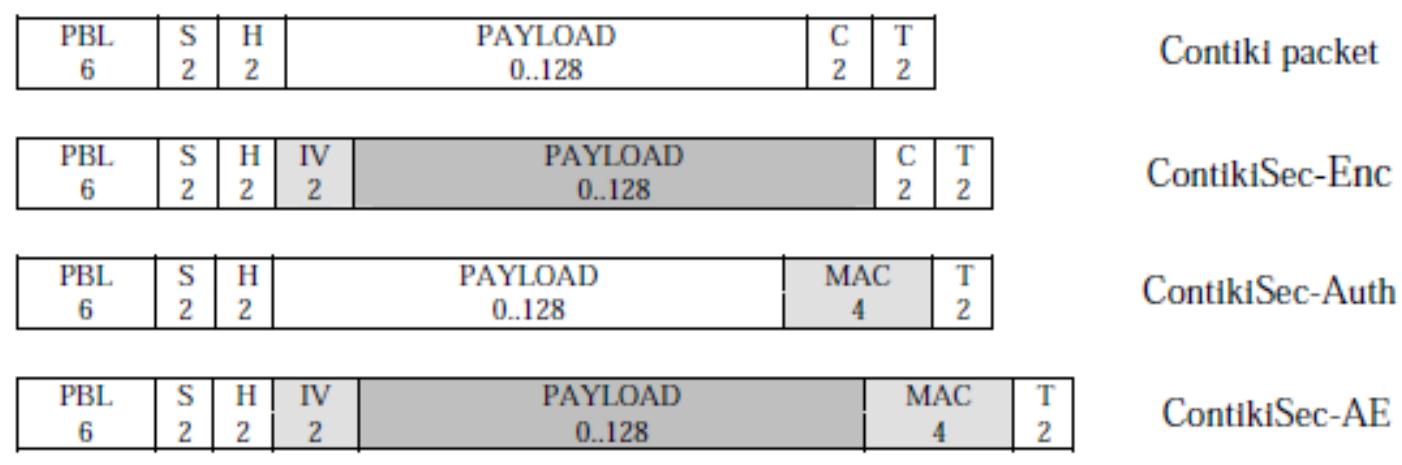

Figura 7: Formatos de pacotes do ContikiSec em comparação com o pacote padrão do sistema operacional Contiki (CASADO; TSIGAS, 2009)

\subsubsection{Segurança do Padrão IEEE 802.15.4}

O padrão IEEE 802.15.4 (IEEE, 2006) especifica os seguintes serviços de segurança a serem implementados na camada de enlace: autenticação e integridade de dados; confidencialidade; e proteção contra repetição. Assim como nas arquiteturas anteriores, estes serviços de segurança são providos através de mecanismos de criptografia simétrica. Os algoritmos utilizados são: AES-128 (DAEMEN; RIJMEN, 2000) como cifra de bloco; o código de autenticação de mensagem é o CBC-MAC; CTR (NIST, 2001) como modo de operação para somente cifração; e o CCM (NIST, 2007) para cifração autenticada.

Essa arquitetura provê oito modos de funcionamento ou conjuntos de segurança (security suites), que são combinações de configurações entre cifração, autenticação e cifração autenticada. A sobrecarga de pacote envolvida é de 5 bytes para cifração, e a adição do tamanho do MAC escolhido para autenticação e integridade. O quadro contido na Figura 8 mostra o conjunto de oito configurações de segurança. 


\begin{tabular}{|c|l|}
\hline Modo & Descrição \\
\hline Nenhum & Sem segurança \\
\hline AES-CTR & Somente cifração, modo CTR \\
\hline AES-CBC-MAC-128 & Autenticação com MAC de 128 bits \\
AES-CBC-MAC-64 & Autenticação com MAC de 64 bits \\
AES-CBC-MAC-32 & Autenticação com MAC de 32 bits \\
\hline AES-CCM-128 & Cifração autenticada com MAC de 128 bits \\
AES-CCM-64 & Cifração autenticada com MAC de 64 bits \\
AES-CCM-32 & Cifração autenticada com MAC de 32 bits \\
\hline
\end{tabular}

Figura 8: Conjunto de configurações de segurança do padrão IEEE 802.15.4 (IEEE, 2006)

\subsection{Análise Comparativa de Arquiteturas de Se- gurança para Redes de Sensores sem Fio}

Uma característica das arquiteturas apresentadas na Seção 3.2 é o vínculo com determinado dispositivo ou sistema operacional. Isto pode ocorrer tanto na fase de projeto, tendo em vista que estas foram projetadas para atuar junto a camadas mais baixas, que por sua vez está atrelada ao dispositivo e ao sistema operacional; quanto na fase de implementação.

As arquiteturas TinySec e MiniSec, por exemplo, foram projetadas para o sistema operacional TinyOS (HILL et al., 2000) e, como observado por Santos (2009), cada uma delas foi implementada para um dispositivo (nó sensor) específico. Já a ContikiSec, foi implementada para o sistema operacional Contiki (DUNKELS; GRONVALL; VOIGT, 2004), e a especificação de segurança do padrão IEEE 802.15.4, por sua vez, foi especificado para tornar-se um padrão na tecnologia, sendo implementado por alguns fabricantes em chipsets de rádio, para entrar em conformidade com o referido padrão. Essas diferenças impossibilitam a interoperabilidade entre as diferentes arquiteturas.

Tais diferenças também tornam a comparação entre as arquiteturas muito complexa, dado que estas não convergem em uma única plataforma, ou seja, não 
há uma configuração em comum, impossibilitando os testes destas sob as mesmas condições, sem envolver a reimplementação, em partes ou completa, das arquiteturas. Além disso, as arquiteturas também podem adotar diferentes abordagens de projeto e implementação, utilizando políticas diferentes em relação a processamento e consumo de memória, alterações de componentes do sistema operacional, caso do MiniSec (SANTOS, 2009), questão ainda mais complexa.

Uma dificuldade adicional a ser mencionada, é que nos último anos, os dispositivos e sistemas operacionais sofreram diversas atualizações, o que não ocorreu com as arquiteturas de segurança. Desta forma, as arquiteturas ficaram indisponíveis para diversas plataformas, como é o caso da TinySec e o MiniSec, não disponíveis para a série 2 do sistema operacional TinyOS (TinyOS versão 2.x).

Além disso, ainda pode ocorrer a indisponibilidade de drivers para o sistema operacional; como foi o caso da especificação de segurança do padrão IEEE 802.15.4 que esteve disponível em alguns dispositivos, como no TelosB (MEMSIC, 2010c) e no MICAz (MEMSIC, 2010a), sem que houvesse drivers para os sistemas operacionais, o que dificulta muito a utilização da arquitetura de segurança.

Considerando que a comparação absoluta das arquiteturas de segurança para RSSFs é extremamente complexa, uma possível abordagem é a análise das estratégias e dos mecanismos criptográficos dos quais estas fazem uso para prover os serviços de segurança. A seguir é apresentada uma análise comparativa da arquiteturas, que baseia-se nas características das mesmas, discutidas na Seção 3.2 e resumidas no quadro comparativo contido na Figura 9. Para esta análise são considerados dois aspectos: segurança e eficiência, cada qual discutida em uma subseção correspondente. 


\begin{tabular}{|l|l|l|l|l|}
\hline & TinySec & MiniSec & ContikiSec & $\begin{array}{l}\text { Padrão IEEE } \\
\mathbf{8 0 2 . 1 5 . 4}\end{array}$ \\
\hline Cifra padrão & Skipjack & Skipjack & AES-128 & AES-128 \\
\hline $\begin{array}{l}\text { Algoritmo } \\
\text { de MAC }\end{array}$ & CBC-MAC & OCB & $\begin{array}{l}\text { OCB ou } \\
\text { CBC-MAC }\end{array}$ & CBC-MAC \\
\hline $\begin{array}{l}\text { Comprimento } \\
\text { do MAC }\end{array}$ & 32 bits & 32 bits & 32 bits & $\begin{array}{l}32,64 \\
\text { ou 128 bits }\end{array}$ \\
\hline $\begin{array}{l}\text { Modo de } \\
\text { Operação }\end{array}$ & $\begin{array}{l}\text { CBC-ciphertext } \\
\text { stealing }\end{array}$ & OCB & $\begin{array}{l}\text { OCB ou } \\
\text { CBC-ciphertext } \\
\text { stealing }\end{array}$ & $\begin{array}{l}\text { CCM ou } \\
\text { CTR }\end{array}$ \\
\hline $\begin{array}{l}\text { Modos de } \\
\text { Funcionamento }\end{array}$ & $\begin{array}{l}\text { I)Somente } \\
\text { Autenticação } \\
\text { II)Cifração } \\
\text { Autenticada }\end{array}$ & Autração & $\begin{array}{l}\text { I)Somente } \\
\text { Autenticação } \\
\text { II)Cifração } \\
\text { Autenticada } \\
\text { III)Somente } \\
\text { Cifração }\end{array}$ & $\begin{array}{l}8 \text { modos, } \\
\text { ver Figura 8 }\end{array}$ \\
\hline $\begin{array}{l}\text { Overhead de } \\
\text { dados na } \\
\text { comunicação }\end{array}$ & $\begin{array}{l}5 \text { bytes (I) ou } \\
1 \text { byte (II) }\end{array}$ & 3 bytes III) & $\begin{array}{l}\text { by bytes }+ \\
\text { ou bytes (II) } \\
\text { código } \\
\text { autenticador }\end{array}$ \\
\hline
\end{tabular}

Figura 9: Propriedades das arquiteturas de segurança analisadas

\subsubsection{Segurança}

As arquiteturas atuantes na camada de enlace são efetivas e essenciais para evitar ataques com objetivos de inundar a rede com dados inúteis, a partir da injeção destes ou do ataque de repetição. Contudo, a abordagem adotada pelas arquiteturas analisadas apresenta uma deficiência em relação à captura de nós e a segurança fim-a-fim, comprometendo a resiliência da mesma.

Como a cifração atua na camada de enlace, protegendo inclusive os dados de roteamento. Desta forma, todos os nós que participam da tarefa de encaminhamento dos dados precisam decifrar, interpretar os dados de roteamento e, por fim, cifrar novamente e encaminhar para o próximo nó da rota em direção ao nó sorvedouro. Desta forma, todos os nós tem acesso às informações de interesse da aplicação, ou seja, se um adversário comprometer um nó qualquer, ele poderá ter acesso a todos os dados que passarem por este nó. 
A Figura 10 apresenta um exemplo no qual o nó de número 4 é comprometido por um adversário, que a partir do momento do comprometimento poderá ter acesso a todos os dados coletados pelos nós 3 e 6 , podendo este nó 4 (comprometido) ler o conteúdo das mensagens a serem repassadas para o nó 5, o que compromete a confidencialidade, e ainda alterar o conteúdo da mesma, comprometendo a integridade dos dados.

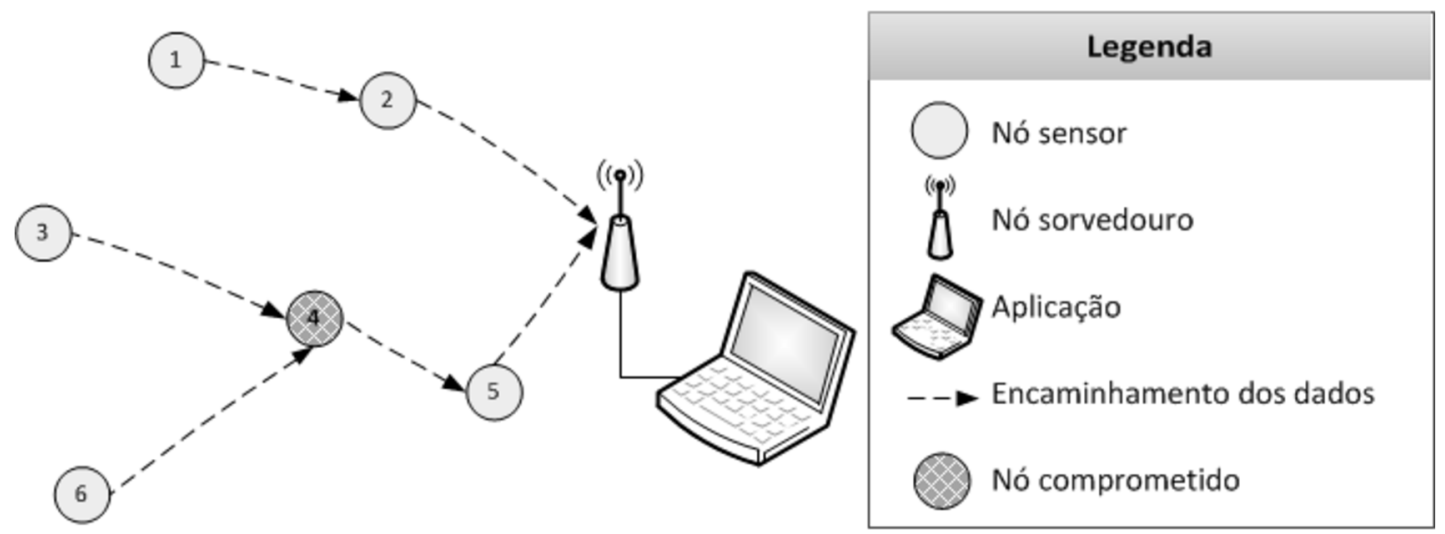

Figura 10: Nó comprometido capaz de executar ataque aos serviços de confidencialidade, autenticidade e integridade

Assim, observa-se que as arquiteturas atuantes na camada de enlace não oferecem segurança fim-a-fim para uma rede de múltiplos saltos.

Em relação aos mecanismos, o mais importante para as arquiteturas de segurança baseadas em criptografia simétrica, como é o caso das arquiteturas analisadas neste trabalho, é a cifra simétrica utilizada. Em geral as arquiteturas de segurança utilizam cifras simétricas de bloco, isto se dá pela maior segurança que este tipo de cifra provê se comparado com as cifras de fluxo. Uma discussão mais completa sobre o assunto pode ser encontrado no trabalho de Simplicio (2008).

Um ponto fraco da TinySec é a utilização da cifra de bloco Skipjack (NSA, 1998) como cifra padrão. Esta decisão foi tomada devido ao tamanho de bloco que a cifra processa (64 bits) e da chave ( 80 bits), sob o argumento que as RSSFs em sua maioria trabalham com pacotes de dados pequenos, o que torna as cifras que trabalham com um conjunto pequenos de dados mais atrativas. Contudo, estudos 
de criptoanálise revelam que o Skipjack possui baixa margem de segurança contra ataques, dado que 31 das 32 rodadas de sua estrutura podem ser criptoanalisadas com sucesso (BIHAM; BIRYUKOV; SHAMIR, 1999).

Esse ponto fraco persistiu na arquitetura MiniSec, tendo seus autores justificado que o Skipjack ainda poderia ser considerado seguro (em 2007). Para contornar esta limitação de segurança, há a opção de modificar as implementações das arquiteturas TinySec e Minisec para utilizar o AES-128 como cifra simétrica subjacente.

Os autores da arquitetura ContikiSec e os colaboradores da especificação de segurança do padrão IEEE 802.15.4, por sua vez, preferiram propor arquiteturas mais seguras, em detrimento do desempenho, utilizando o AES-128 (bloco e chave de 128 bits).

Outro ponto fraco de segurança da TinySec é referente a utilização do modo de operação CBC. Para maximizar a segurança desse modo de operação é necessário que o vetor de inicialização (VI), além de não se repetir, seja imprevisível para um adversário (LUK et al., 2007). Este requisito de imprevisibilidade não é atendido na TinySec, dado que a arquitetura garante a não repetição do VI a partir da utilização de um contador que é incrementado a cada pacote enviado, o que torna o VI extremamente previsível.

Esse ponto fraco não permaneceu nas propostas da MiniSec e da ContikiSec (no modo ContikiSec-AE), que utilizam o $\mathrm{OCB}$, que não precisa de VI imprevisível, como mecanismo de cifração autenticada. O modo CCM, utilizado na especificação de segurança do IEEE 802.15.4, também não apresenta esse requisito.

A segurança de autenticação de origem e integridade dos dados no tipo de mecanismo utilizado pelas arquiteturas analisadas, código de autenticação de 
mensagem, é baseada no tamanho do código autenticador, que deve ser escolhido de acordo com o requisito de segurança. Segundo Luk et al. (2007), a probabilidade de um adversário forjar uma mensagem autenticada é de $2^{-t}$, onde $t$ é o comprimento do código autenticador (em bits). Com a utilização de um código autenticador de 4 bytes (32 bits), como é o caso das arquiteturas TinySec, MiniSec e ContikiSec, a chance de um adversário forjar uma autenticação é suficientemente remota (uma chance em 4.294.967.296 tentativas). O autor argumenta que esse nível de segurança é suficiente, mas segundo NIST (2007) o comprimento do código autenticador deve ser de 64, 96 ou 128 bits.

\subsubsection{Eficiência}

A busca pela eficiência das arquiteturas de segurança para RSSFs tem dois principais objetivos. O primeiro é maximizar o tempo de vida dos nós sensores em relação ao suprimento de energia, dado que em sua maioria o nós sensores são alimentados por baterias, sendo necessário que os mecanismos sejam dimensionados para consumir o mínimo de energia possível. O segundo objetivo é proporcionar aos nós sensores uma capacidade de responder em um tempo aceitável de acordo com a aplicação. Como diversas aplicações são baseadas em eventos, o ideal é que os mecanismos garantam o nível de segurança necessário, introduzindo o mínimo atraso possível para não degradar o desempenho das aplicações.

Para analisar as arquiteturas em relação a esses objetivos, pode-se considerar o overhead de comunicação e o overhead de processamento introduzidos pelas mesmas. O overhead de comunicação é dado pelo aumento do tamanho dos pacotes de comunicação, e o overhead de processamento é dado pela demanda de processamento dos mecanismos. 


\subsubsection{Overhead de Comunicação}

As arquiteturas precisam adicionar dados de controles a serem transmitidos junto com os dados protegidos por seus mecanismos, para indicar como os nós receptores devem processar os pacotes e enviar parâmetros quando necessário.

A TinySec, no modo TinySec-Auth, adiciona 1 byte referente ao código autenticador. É importante notar que o código autenticador tem 4 bytes, mas a arquitetura eliminou o CRC (2 bytes) e o campo de grupo (1 byte). Para o modo de cifração autenticada são adicionados 5 bytes, pois além do byte do modo de autenticação são adicionados outros 2 bytes do contador do VI e 2 bytes para o endereço do remetente (o que não seria necessário na versão atual do TinyOS, pois o mesmo já possui um campo de endereço de origem no seu pacote seguindo o padrão IEEE 802.15.4).

O overhead de comunicação introduzido pela MiniSec é menor, apenas 3 bytes. Ela altera o pacote da mesma forma que a TinySec, inclusive incluindo o campo de endereço de origem, mas deixa de utilizar o campo de contador (2 bytes). Isso se deve a um esquema de sincronismo que a arquitetura utiliza, os contadores entre dois nós são sincronizados na montagem da rede, e a cada mensagem trocada os interlocutores incrementam esse contador, que é utilizado como vetor de inicialização (VI).

Essa estratégia é interessante no que diz respeito a redução do overhead de comunicação, mas perdas de pacotes podem comprometer o funcionamento do esquema, tornando o mesmo menos tolerante a perdas. Para minimizar este problema a arquitetura utiliza como sincronizador 3 bits do campo de tamanho (LEN) de 1 byte, pois dado que na versão 1 do TinyOS o tamanho máximo de um pacote de dados úteis é de 30 bytes, é possível representar o tamanho do pacote com apenas 5 bits. Esse sincronizador não seria possível na versão 2 do 
TinyOS, que apresenta um pacote com tamanho máximo de dados úteis de 114 bytes. Outro detalhe a ser levado em consideração é que, utilizando a MiniSec, se algum nó da rede receber mensagens de muitos nós diferentes, as estruturas de dados utilizadas pelo esquema de sincronismo podem passar a ocupar uma grande quantidade de bytes de memória, outro recurso limitado nas RSSFs.

O projeto da ContikiSec inclui 2 bytes para os modos que utilizam cifração e 2 bytes para os modos que utilizam autenticação, por consequência o modo de cifração autenticada inclui 4 bytes. O código autenticador desta arquitetura também tem comprimento de 4 bytes, mas esta arquitetura também elimina o campo de CRC (2 bytes).

Atualmente grande parte dos módulos de rádio, que estão em conformidade com o padrão IEEE 802.15.4, ou seja, têm o CRC implementado em hardware. Assim, seria impossível substituir este campo pelo código autenticador, o que implica no custo de mais 2 bytes para as arquiteturas TinySec, MiniSec e ContikiSec quando utilizado o serviço de autenticação em sensores com módulos de rádio em conformidade com o referido padrão.

A especificação de segurança do padrão IEEE 802.15.4, entre as arquiteturas comparadas, é a que mais introduz overhead de comunicação, adicionando 5 bytes para utilizar na cifração e no mínimo 4 bytes para o código autenticador.

Ainda, na análise da overhead de comunicação há outra limitação a ser considerada. As arquiteturas que utilizam o CBC-ciphertext stealing (TinySec e ContikiSec no modo somente cifração) não são capazes de enviar mensagens menores que um bloco da cifra. Assim quando uma mensagem é menor que o tamanho deste bloco, o modo de operação precisa preencher o restante (padding) para que a mesma fique do tamanho do referido bloco. Essa é uma necessidade inerente ao $C B C$-ciphertext stealing. 
Os modos de operação OCB e CCM não necessitam da adição de "enchimento" aos blocos de texto claro, o que os permite produzir texto cifrado do mesmo comprimento do texto claro original, mesmo quando este último não tem comprimento múltiplo do bloco da cifra. Desta forma, a mensagem cifrada ficará do mesmo comprimento da mensagem não cifrada, seja qual for o tamanho deste, economizando na transmissão de rádio. Esses mecanismos adotam uma estratégia que simula uma cifra de fluxo, nela um bloco derivado do vetor de inicialização é cifrado, e então é efetuada a operação de ou exclusivo com a mensagem a ser cifrada.

\subsubsection{Overhead de Processamento}

Esquemas atuantes na camada de enlace resultam em overhead de processamento para a rede inteira, pois todos os nós que fazem os encaminhamentos das mensagens precisam executar tarefas de cifração e decifração, além de verificar e gerar códigos autenticadores a cada encaminhamento.

O overhead de processamento impacta nos dois objetivos da busca por maior eficiência dessas arquiteturas, o consumo de energia e o tempo de resposta dos nós. Contudo, o impacto sobre o tempo de resposta é muito maior do que sobre a energia consumida, pois o processador consome bem menos energia que o módulo de rádio e as tarefas que envolvem rádio levam muito mais tempo. Observando os resultados apresentados no trabalho (MARGI et al., 2010), é possível estimar que uma cifração AES-128 (que trabalha sobre 16 bytes) leva 166 vezes menos tempo que uma transmissão de 12 bytes, e consome 1650 vezes menos energia.

Com relação aos modos de operação utilizados nas arquiteturas, o trabalho de Jinwala et al. (JINWALA; PATEL; DASGUPTA, 2009) apresenta uma comparação entre o CBC, OCB e CCM. Os resultados apontam OCB é aproximadamente 
$30 \%$ mais eficiente que o CBC e $35 \%$ mais eficiente que o CCM.

A partir dos resultados de comparação é possível observar que a escolha da TinySec não foi muito interessante, ainda mais quando consideradas as limitações de segurança e tamanho de mensagem discutidas anteriormente.

Segundo os autores da Minisec, o OCB em uma única "passada" pelo bloco de mensagem cifra e calcula o código autenticador simultaneamente, levando vantagem sobre o $C B C$-ciphertext stealing com CBC-MAC e CCM que necessitam de uma execução para cifrar a mensagem e outra para gerar o código de autenticação de mensagem.

A ContikiSec segue a mesma linha da MiniSec, utilizando o OCB para cifração autenticada, o que pode garantir uma boa eficiência para a arquitetura. A especificação de segurança do padrão IEEE 802.15.4 utiliza o modo de operação de menor eficiência entre os comparados. O CCM é composto pelo modo CTR e o CBC-MAC, algoritmos mais tradicionais, o que pode ser traduzido como maior confiabilidade, dado que esses algoritmos já foram submetidos a um maior número de testes e tentativas de ataques.

\subsubsection{Considerações sobre as arquiteturas analisadas}

As discussões contidas nesta seção apontam que a TinySec e a MiniSec apresentam pontos fracos de segurança pelo uso do SkipJack. Assim como a TinySec e a ContikiSec (somente cifração) pela utilização do CBC sem um vetor de inicialização imprevisível.

A arquitetura MiniSec é a que provê proteção de repetição de forma mais efetiva e introduz menor sobrecarga na comunicação, o que é muito interessante no sentido de economia de energia, mas que pode ter um impacto negativo em redes com perdas de pacotes, por conta do mecanismo dependente de sincronismo. 
As arquiteturas de segurança atuantes em camadas mais baixas, associadas aos sistemas operacionais (SOs), são muito suscetíveis a indisponibilidade de implementação e incompatibilidade por atualizações nos SOs. Por outro lado, a arquitetura de segurança baseada em componentes de hardware é suscetível a indisponibilidade de drivers, mas com a crescente adesão aos padrões a tendência é que estes drivers passem a ser disponibilizados na maioria dos SOs.

O custo energético da comunicação é muito maior do que o do processamento. Desta forma, arquiteturas que adicionam mais carga extra para transmissão são muito mais nocivas do que as que demandam mais processamento. A melhor opção pode ser a escolha de um algoritmo mais seguro, mesmo que este cause overhead de processamento, pois a segurança fraca pode não justificar a adição de overhead na comunicação. 


\section{ANÁLISE DE ABORDAGENS DE DISTRIBUIÇÃO DE CHAVES}

Um aspecto crucial para o uso de mecanismos de segurança baseados em criptografia simétrica, como é o caso das arquiteturas de segurança projetadas para RSSFs analisadas neste trabalho é a forma como as chaves criptográficas simétricas são distribuídas.

A abordagem de distribuição mais simples que pode ser utilizada é a atribuição de uma única chave para a rede inteira, denominada chave global. Esta é adicionada aos nós sensores no momento de sua programação, antes da disposição dos nós em seu local de sensoriamento. Todavia, como há muitas aplicações nas quais os nós sensores precisam permanecer em locais sem proteção física, ou seja, expostos e sujeitos a captura e comprometimento, tal abordagem não é adequada, dado que a leitura da memória de um único nó sensor comprometido revela a chave global, afetando a segurança de toda a rede.

Neste capítulo são apresentadas as abordagens para distribuição de chaves criptográficas em RSSFs e uma discussão sobre o impacto das topologias e das características de disposição neste processo.

\subsection{Tipos de Distribuição de Chaves em RSSFs}

Atualmente a literatura conta com diversas propostas para distribuição de chaves criptográficas voltadas a RSSFs. Carman, Kruus e Matt (2000) agrupam 
estas soluções de distribuição de chaves em três tipos em função de suas características: esquemas de pré-distribuição, esquemas auto-regulados e esquemas arbitrados.

A seguir são apresentadas as características de cada um desses grupos de abordagens de distribuição de chaves, dando uma visão geral do funcionamento e analisando cada um destes. Antes disso, são apresentados requisitos e métricas que são considerados na avaliação das abordagens.

\subsubsection{Requisitos e Métricas}

Esquemas de distribuição de chaves criptográficas em RSSFs são avaliados por meio de diversas métricas, levando em consideração diferentes requisitos, que geralmente são conflitantes. Essas métricas podem ser classificadas em três grupos distintos: segurança, eficiência e flexibilidade (MARGI et al., 2009).

As métricas de segurança estão associadas à capacidade de resistir a ataques. Sendo assim, os esquemas de distribuição de chaves devem, além de prevenir que entidades adversárias da rede descubram as chaves utilizadas pelos nós, também garantir que a captura física de um nó tenha um impacto reduzido nas comunicações às quais este nó não está envolvido, ou seja, a captura de um nó não deve prejudicar a comunicação dos demais nós, este fator é conhecido como resiliência à captura de nós. Ademais, os esquemas devem prover autenticação segura dos nós, de forma que um nó intruso não consiga se passar por um nó válido da rede. Finalmente, quando necessário, entidades confiáveis, e somente elas, devem ser capazes de atualizar as chaves dos nós da rede.

As métricas de eficiência estão diretamente relacionadas com as restrições de hardware dos nós sensores da rede. Idealmente, todos os sensores que estejam dentro da mesma área de alcance de suas antenas devem ser capazes de compartilhar uma chave entre si para que a comunicação esteja segura. Portanto, 
os esquemas de gerenciamento de chaves devem resultar em redes com um bom nível de conectividade de chave e não devem causar um impacto significativo na utilização de processamento, memória, comunicação e energia.

Ainda em relação a conectividade, é importante ressaltar que as arquiteturas de segurança que atuam na camada de enlace requerem que os nós da rede compartilhem chaves criptográficas com todos nós ao seu alcance, do contrário não é possível estabelecer comunicação entre eles, nem mesmo para executar o repasse de pacotes em uma tarefa de roteamento, particionando assim a rede.

Por fim, a flexibilidade dos esquemas de distribuição de chaves é medida pela sua capacidade de ser implementada em uma ampla gama de cenários e aplicações. Em geral é desejável que a eficácia destes não dependam de informações difíceis de serem obtidas antes que a rede seja efetivamente montada. Por exemplo, em aplicações nas quais os sensores são distribuídos sobre o terreno alvo de forma aleatória, não determinística, é muito complexo predizer o posicionamento final de um determinado nó, ou mesmo quais são os nós adjacentes a ele, ou seja, quais nós comporão sua vizinhança.

Além disso, é importante considerar a escalabilidade do esquema já que o tamanho da rede pode variar de forma bastante dinâmica, ao longo de sua vida útil. Portanto, as soluções mais flexíveis são aquelas que não dependem de informação de localização dos nós, que são capazes de suportar redes com um grande número de sensores e que permitem a introdução dinâmica de nós na rede sem impactos na sua segurança.

\subsubsection{Esquemas de Pré-distribuição}

Neste tipo de esquema as chaves criptográficas a serem utilizadas são carregadas na memória dos nós sensores antes que a rede seja montada. Esta estratégia evita o uso de protocolos complexos para o compartilhamento de chaves entre 
nós, garantindo uma boa eficiência. Ademais, ela possibilita uma rede pouco dependente de nós coordenadores, já que todo o material criptográfico necessário para garantir a segurança das comunicações já está disponível nos sensores.

Por outro lado, a adoção desse tipo de abordagem adiciona extrema complexidade para a troca de chaves, e também para a implantação das chaves na rede. Uma forma simples de compreender a dificuldade de implantação de um esquema de pré-distribuição é observar os dois extremos de possibilidades do mesmo.

Em um extremo está a utilização de uma única chave para a rede inteira, chave global, que proporciona um ótimo desempenho e flexibilidade, mas não provê resiliência à captura e nem forte autenticação, tendo em vista que só é possível garantir que dada mensagem foi enviada por alguém que conhece a chave, podendo ser qualquer nó sensor da rede, inclusive um nó que por ventura tenha sido capturado.

No outro extremo está a distribuição de uma chave por par de nós, de forma que cada nó da rede possua uma chave para se comunicar com qualquer outro nó da rede, ou com os nós que estão ao seu alcance. Essa abordagem provê total resiliência e conectividade de chave, forte autenticação, mas prejudica a escalabilidade, sendo muito oneroso adicionar um novo nó na rede. Além disso, compromete o desempenho em relação ao uso de memória, dado que em uma rede com $n$ nós, cada nó precisa armazenar $n-1$ chaves criptográficas. A implantação pode ser complicada, pois o número de chaves a ser distribuída cresce muito rápido em relação ao número de nós na rede, mais especificamente $(n(n-1)) / 2$ chaves a serem distribuídas, onde $n$ é o número de nós sensores na rede.

Uma alternativa a estes dois extremos é a utilização da localização dos nós para distribuir as chaves de forma que os nós armazenem apenas as chaves criptográficas para comunicação com os seus vizinhos. Assim obtém-se total resiliência, autenticação, e um desempenho razoável em relação à ocupação de memória, 
porém permanece o problema de escalabilidade e introduz-se a limitação de necessário conhecer a localização dos nós previamente.

Ainda há outras diversas propostas baseadas em pré-distribuição utilizando fator de aleatoriedade. Um exemplo é o esquema proposto por Eschenauer e Gligor (2002), no qual chaves compartilhadas entre diversos nós, como chaves de grupos, são selecionadas aleatoriamente a partir de um conjunto inicial, o que reduz o uso de memória ao custo de prejudicar a conectividade (pares de nós podem não possuir uma chave em comum) e resiliência (a captura de um nó revela diversas chaves sendo utilizadas pela rede).

\subsubsection{Esquemas Arbitrados}

Os esquemas arbitrados lançam mão da utilização de nós especiais, com maior responsabilidade do que nós sensores comuns, para estabelecer e gerenciar as chaves da rede. Tal abordagem mostra-se bastante atrativa caso entidades com maior poder de processamento estejam disponíveis na rede, pois elas podem concentrar o ônus de processamento de operações complexas e a consequente transmissão das chaves. Esse costuma ser o caso de RSSF hierárquicas, nas quais as entidades em questão costumam ser estações-base ou líderes de grupo.

O maior risco associado a esse tipo de abordagem é que as entidades que executam a tarefa de distribuição de chaves costumam tornar-se um alvo preferencial de ataques, que afetariam uma parcela considerável da rede caso sejam bem sucedidos.

\subsubsection{Esquemas Auto-Regulados}

Os esquemas auto-regulados utilizam criptografia assimétrica para estabelecer (ou compartilhar) chaves criptográficas entre pares de sensores de forma dinâmica após a formação da rede. Esta característica torna os esquemas auto- 
regulados altamente atrativos, principalmente em cenários nos quais a topologia da rede altera-se com frequência, como em topologias com nós móveis ou com a necessidade de adição dinâmica de nós.

Outra vantagem que o esquema traz é redução da quantidade de informação armazenada sobre as chaves em cada sensor, no caso mais purista, inicialmente apenas o par de chaves (pública e privada). Esta abordagem proporciona uma elevada resiliência, e possibilita a eliminação da existência de pontos centrais confiáveis que se tornariam alvos preferenciais de ataques.

Todavia, durante muito tempo os esquemas auto-regulados foram considerados não praticáveis em RSSFs, por conta do desempenho dos algoritmos de criptografia assimétrica. Mas com o recente desenvolvimento de soluções assimétricas baseados em criptografia de curvas elípticas, os esquemas auto-regulados passaram a receber uma maior atenção. De acordo com implementação e análise recentes, como a de Aranha et al. (2009), mostram que o tempo necessário para calcular um emparelhamento (o processo geralmente mais dispendioso neste tipo de solução) em um sensor MICAz (MEMSIC, 2010a) pode chegar a 2 s.

O uso de criptografia de curvas elípticas em RSSFs é ainda mais atrativo quando estas soluções são combinadas como protocolos criptográficos baseados em identidades, nos quais a chave pública do nó corresponde sua identificação, como o endereço físico ou de rede, ou algo derivado desta identificação. Um exemplo para este tipo de abordagem em RSSFs é o proposto por Oliveira et al. (2010), baseada no protocolo de Sakai, Ohgishi e Kasahara (2000), no qual é explorada a bilinearidade das curvas elípticas (função $e$ ) provendo o emparelhamento bilinear a partir da propriedade apresentada na seguinte Equação 4.1.

$$
e([a] P,[b] Q)=e(P,[b] Q)^{a}=e([a] P, Q)^{b}=e(P, Q)^{a b}
$$


Para iniciar o esquema de criptografia baseada em identidade, tirando proveito desta propriedade bilinear, uma autoridade confiável, que no caso das RSSFs é o nó sorvedouro, precisa distribuir a chave privada $(S X)$ correspondente a identidade pública $(P X)$ para cada nó. Para isto a própria autoridade confiável gera uma chave-mestra, que só ela conhece, e a partir da qual é extraída a chave privada $(S X=[s] P X)$ de cada nó. Neste contexto, o nó sorvedouro é chamada de Centro de Distribuição de Chaves (CDC).

A operação de geração da chave-mestra e a extração das chaves privadas são as operações mais custosas do esquema em questão. Desta forma, manter esses procedimentos em responsabilidade do nó sorvedouro, que costuma ter um hardware mais poderoso, é uma estratégia promissora para as RSSFs. No exemplo de protocolo citado, a distribuição das chaves privadas é efetuada no momento da programação de cada nó, como é feita nas abordagens de pré-distribuição.

A partir do esquema descrito, todos os nós cujas chaves privadas tenham sido geradas por um mesmo CDC podem gerar uma chave compartilhada simplesmente sabendo a identidade de seu interlocutor, de forma não interativa, evitando o overhead de comunicação. O conjunto de equações (da Equação 4.2 a Equação 4.6) a seguir apresentam matematicamente este processo:

$$
\begin{array}{r}
\hat{e}\left(S_{A}, P_{B}\right)=\hat{e}\left([s] P_{A}, P_{B}\right) \\
=\hat{e}\left(P_{A}, P_{B}\right)^{s} \\
=\hat{e}\left(P_{A},[s] P_{B}\right) \\
=\hat{e}\left(P_{A}, S_{B}\right) \\
=\hat{e}\left(S_{B}, P_{A}\right)
\end{array}
$$

Note que, ê é a função de emparelhamento, $[s] P A=S A$; onde $S A$ é a chave 
privada do nó $A$ e $P A$ é a chave pública do nó $A,[s] P B=S B$, onde $S B$ é a chave privada do nó $B$ e $P B$ é a chave pública do nó $B$. Assim, a chave criptográfica simétrica $\left(k_{A, B}\right)$, compartilhada entre o nó $A$ e o nó $B$ é dada pela seguinte função representada na Equação 4.7.

$$
k_{A, B}=\hat{e}\left(S_{A}, P_{B}\right)=\hat{e}\left(S_{B}, P_{A}\right)
$$

Desta forma os dois nós podem calcular a chave a ser utilizada no esquema de criptografia simétrica, para a comunicação entre eles, conhecendo apenas sua própria chave privada e a chave pública do interlocutor, que neste caso é a identidade do mesmo, caracterizando um esquema de distribuição de chaves não-interativo, o que é muito interessante para RSSFs dado que a comunicação é a atividade que costuma consumir mais energia.

\subsection{Análise Comparativa}

A análise apresentada nesta seção é calcada nas discussões sobre as abordagens de distribuição de chaves criptográficas apresentadas na Seção 4.1. A discussão que segue é norteada por três aspectos:

- as métricas e requisitos apresentados na Seção 4.1.1;

- a exposição do nó, em relação à possibilidade de captura do mesmo;

- necessidades de segurança das topologias da rede de sensores sem fio.

Primeiramente discute-se o caso das aplicações implantadas em ambientes protegidos e com baixa probabilidade de captura de nós. A partir desse ponto conduz-se a discussão supondo que as topologias são suscetíveis a captura de nós, com média ou alta probabilidade da mesma ocorrer. 
Desta forma, a discussão segue utilizando as diferentes topologias como ponto central, e adicionando comentários referentes a possíveis necessidades de segurança das aplicações que podem estar associadas a determinada topologia. Para esta fase da discussão são consideradas três diferentes tipos de topologias: plana, hierárquica e estacionária com sorvedouro itinerante. A Figura 11 contém uma taxonomia relacionando essas topologias.

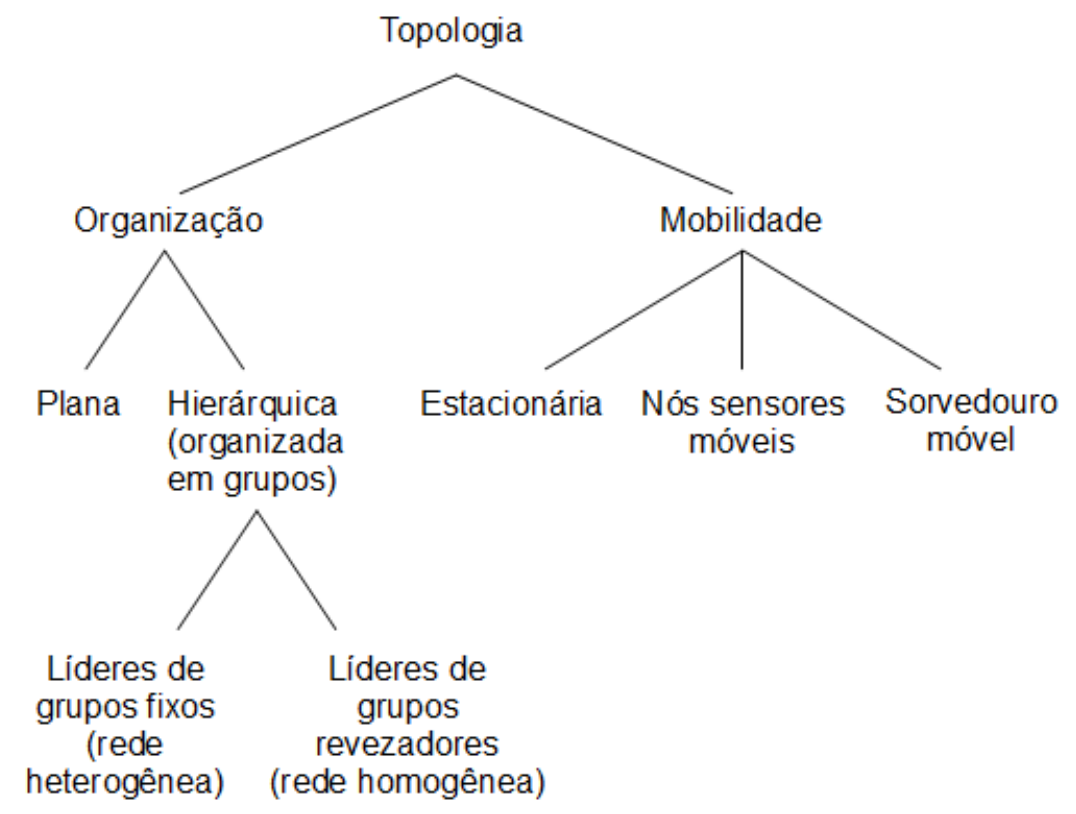

Figura 11: Taxonomia de topologias de redes de sensores sem fio

Outro detalhe que será considerado, é que o consumo de memória dos esquemas auto-regulados é médio, como discutido na avaliação já mencionada (ARANHA et al., 2009), que considera o estado-da-arte em ECC com tempo de execução em 2 s, mostrando que a memória consumida é de 400 bytes. Isso é equivalente a 25 chaves criptográficas de um esquema de cifra de bloco que utiliza o algoritmo AES-128.

\subsubsection{Aplicações Pouco Suscetíveis a Captura de Nós}

Diversas aplicações, muito referenciadas pelo termo indoor como controle do clima, vigilância, monitoramento de pacientes em um quarto de hospital e 
controle de estado de máquinas em indústrias, podem ser consideradas como pouco suscetíveis a captura de nós da rede, tendo em vista que geralmente esses ambientes são vigiados e o roubo de um sensor seria facilmente notado. A maior vulnerabilidade para essas aplicações são as relacionadas a comunicação, que pode ser monitorada a distância por equipamentos mais potentes que os nós sensores.

Desta forma, é possível descartar a resiliência à captura de nós como métrica para avaliar o método de distribuição de chaves. Assim é possível afirmar que um esquema de pré-distribuição com uma única chave provê segurança o suficiente para a aplicação, sendo a mais adequada por conta do baixo consumo de memória e a alta flexibilidade.

Outra opção interessante seria mesclar esse esquema com um esquema arbitrado, de modo que a permitir que nó sorvedouro troque a chave da rede inteira quando necessário.

\subsubsection{Topologia Plana}

Em RSSF de topologia plana (OLIVEIRA, 2009), todos os nós sensores possuem responsabilidades semelhantes no sensoriamento, processamento de dados e roteamento. Em geral, todos os sensores operam com raio de transmissão limitado para poupar energia e atuam de forma colaborativa para encaminhar os dados coletados na rede para o nó sorvedouro através de roteamento por múltiplos saltos.

Para esse tipo de topologia, pode-se considerar os três tipos de distribuição de chaves. Conhecer o posicionamento final do sensor poderia indicar a vantagem de um esquema com pré-distribuição de chaves por localização. Mas se os sensores são móveis ou distribuídos aleatoriamente pelo terreno esta não é uma alternativa viável. 
Não conhecendo a distribuição dos sensores, mas tendo a certeza que a autoridade confiável (nó sorvedouro) estará sempre disponível, seria atrativo um esquema arbitrado, já que a distribuição pode ser feita após a montagem da rede. Para esta afirmação é suposto que o nó sorvedouro está imune a captura, pois se a mesma for capturada a rede perde sua funcionalidade, tendo em vista que todos os dados são encaminhados para ela.

\subsubsection{Topologia Hierárquica}

Em RSSF de topologia hierárquica (OLIVEIRA, 2009), a rede em geral é organizada em grupos, nos quais líderes e membros comuns de grupos têm diferentes responsabilidades. Os membros comuns são responsáveis pela tarefas de sensoriamento e o repasse dos dados para o líder de grupo. Os líderes de grupos são responsáveis por tarefas adicionais, como agregação de dados, para reduzir o tráfego na rede, a solicitação de dados e agendamento de tarefas para os membros comuns, e o repasse dos dados para o nó sorvedouro.

Para este cenário há duas variações, o líder de grupo pode ser fixo ou escolhido por revezamento. Em geral quando o líder de grupo é fixo, o mesmo se trata de um dispositivo mais poderoso do que os demais. Já no esquema de revezamento os nós são iguais, e revezam para dividir o overhead, objetivando o equilíbrio em relação a distribuição do consumo de energia na rede.

Em relação ao esquema de líder de grupo fixo, os esquemas arbitrados parecem ser os mais adequados, pois o risco que ele impõe é o ataque a estes líderes de grupo que são responsáveis nestes esquemas por distribuir as chaves. Contudo, os líderes de grupos podem ser considerados a autoridades confiáveis, dado que todos os nós de determinado grupo enviam seus dados para seu líder correspondente, e o comprometimento do mesmo anula a funcionalidade do grupo inteiro. Assim o risco não é introduzido pelo método de distribuição de chave, ele é inerente 
a arquitetura. Logo a melhor opção é aproveitar os benefícios dos esquemas arbitrados.

Para as arquiteturas hierárquicas com líderes que revezem, é complicado fazer uma pré-distribuição de chaves, tendo em vista que a rede muda de configuração. Um esquema arbitrado é complexo de implementar, tendo em vista que todos os nós candidatos a líder precisariam ser capazes de gerenciar as chaves. Desta forma a melhor opção para esta arquitetura são os esquemas auto-regulados.

\subsubsection{Topologia Estacionária com Sorvedouro Itinerante}

A arquitetura com sorvedouro itinerante trata-se de uma medida para coletar os dados quando não é possível manter o nó sorvedouro no local da coleta dos dados. Os sorvedouros itinerantes fazem a interface entre o nó sorvedouro e os nós sensores, coletando periodicamente, ou mesmo aleatoriamente, os dados de sensoriamento coletados pelos nós da rede e entregando-os ao nó sorvedouro. Um exemplo de aplicação desta arquitetura pode ser encontrado em (SHAH et al., 2003), no qual é proposta a utilização de veículos e até animais para fazerem o papel de sorvedouro itinerante.

Para esse tipo de topologia é muito complicado utilizar pré-distribuição ou esquemas arbitrados, tendo em vista que impostores podem tentar passar-se pelos sorvedouros itinerantes. Também pode haver a necessidade de adicionar novos sorvedouro itinerantes, tendo em vista que estes podem ser facilmente perdidos já que a proposta é utilizá-los fixados a animais ou veículos. Desta forma a solução ideal para este tipo de arquitetura é o esquema auto-regulado. 


\subsection{Considerações do Capítulo}

A partir da análise apresentada neste capítulo é possível observar que apesar dos esquema auto-regulados terem evoluído muito nos últimos anos, os esquemas de pré-distribuição e os arbitrados, principalmente para redes hierárquicas, ainda são opções a serem consideradas.

Contudo é preciso tomar cuidado com esses esquemas, pois são mais complexos de implantar do que os esquemas auto-regulados. Isso pode ferir um dos princípios mais importantes de projetos de segurança apresentados por Bishop (BISHOP, 2003), a simplicidade, de forma que a complexidade pode causar erros na utilização desses mecanismos.

Outra questão observada é que há a tendência de que os esquemas autoregulados realmente sejam uma solução definitiva para a distribuição de chaves em RSSFs. 


\section{ARQUITETURA PROPOSTA}

Neste capítulo são apresentados os detalhes do processo de especificação da arquitetura de segurança prosposta neste trabalho. A Seção 5.1 contém uma visão geral das características consideradas e dos mecanismos selecionados a partir da revisão da literatura para a concepção da arquitetura. Na Seção 5.2 são apresentados os detalhes de especificação de projeto, como modos de funcionamento e formato de pacote, e na Seção 5.3 é discutida e detalhada a seleção dos algoritmos para a implementação da arquitetura. Na Seção 5.4, que finaliza o capítulo, discute-se a implementação da prova de conceito utilizada para validar a arquitetura.

\subsection{Visão Geral}

Dadas as propriedade e requisitos de segurança já discutidos, bem como as técnicas utilizadas pelas soluções de seguranças para RSSFs encontradas na literatura, esta seção introduz a especificação para a arquitetura de segurança proposta neste trabalho, bem como uma breve síntese da justificativa para a escolha dos mecanismos e estratégias selecionados.

Os requisitos relacionados a autenticidade de origem e integridade de dados são atendidos por um mecanismo de código de autenticação de mensagem, técnica já utilizada nas arquiteturas de segurança propostas anteriormente. Como discutido no Capítulo 2, o código de autenticação de mensagem é um mecanismo 
de criptografia que fornece uma verificação segura, onde apenas as entidades que conhecem o segredo, uma chave criptográfica compartilhada, são capazes de gerar um código autenticador de uma determinada mensagem. Então, o código autenticador é anexado à mensagem e o receptor, que conhece a chave compartilhada, é capaz de verificar se a mensagem foi gerada por um portador da chave e esta mensagem não foi modificada durante sua transmissão.

Para obter o serviço de confidencialidade, foi empregado um mecanismo de cifração simétrica, uma vez que esta abordagem apresenta melhor desempenho se comparado com mecanismos assimétricos. Além disso, é utilizada uma cifra de bloco, dado que este tipo de cifra apresenta maior segurança que as cifras de fluxo (SIMPLICIO, 2008).

Por fim, os requisitos de segurança semântica são atendidos através da utilização de um vetor de inicialização (VI), que é usado como uma entrada do modo de operação de cifra de bloco. Este mecanismo permite que uma mensagem de comprimento arbitrário seja processada por uma cifra de bloco (que opera em um número fixo de bits). Parte do vetor de inicialização é um contador que é incrementado a cada mensagem enviada, criando assim, um número utilizado uma única vez (NONCE), permitindo a codificação do texto cifrado independente do texto claro, que por sua vez permite a repetição de texto claro sem que o texto cifrado revele esta repetição. No entanto, apenas a utilização do NONCE não é suficiente para garantir a segurança semântica para todos os modos de operação de cifra de bloco. Por exemplo, no modo Cipher Block Chaining (CBC) o vetor de inicialização deve ser imprevisível e, portanto, a abordagem de usar um contador incremental não garante a segurança semântica forte. Portanto, é necessário selecionar um modo de operação no qual o uso de um NONCE atenda o requisito de segurança semântica, como OCB, utilizado na arquitetura Minisec. 


\subsection{Detalhes de Especificação}

Para prover flexibilidade em relação a utilização dos serviços de segurança, a arquitetura proposta inclui quatro modos de funcionamento, cada qual com uma diferente combinação de serviços de segurança. São eles:

- Somente cifração - modo de funcionamento que provê o serviço de confidencialidade dos dados, incluindo o serviço de segurança semântica, através da utilização de um modo de operação com uma cifra de bloco subjacente. Este modo deve ser utilizado com cautela, dado que não é possível garantir que não houve alterações nos dados durante a transmissão. Outro detalhe importante que deve ser observado com cautela são as restrições de utilização do vetor de inicialização, o parâmetro de entrada utilizado para garantir a segurança semântica.

- Autenticação - modo que fornece os serviços de integridade dos dados e autenticação de origem a partir do emprego de um algoritmo de código de autenticação de mensagem, utilizado para gerar o código autenticador enviado anexado à mensagem pelo nó emissor e processado para conferência no nó receptor, resultando em um overhead de transmissão de dados de acordo com o nível de segurança selecionado. Os dados enviados com a utilização deste modo são transmitidos em forma de texto claro, ou seja, não são cifrados.

- Cifração autenticada - é a combinação dos dois modos anteriores, fornecendo os serviços de confidencialidade, integridade e autenticação de origem dos dados. Também implica em um overhead de transmissão de dados correspondente ao código autenticador.

- Sem segurança - modo que não oferece nenhum serviço de segurança. 
Este modo pode ser utilizado caso o projetista da rede julgue que alguns dados não requerem, ou em algum momento deixaram de requerer, o uso de serviços de segurança.

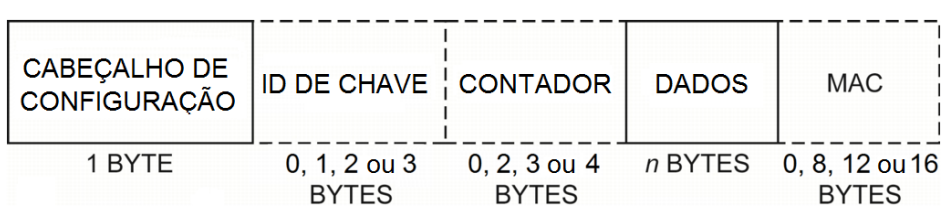

Figura 12: Formato do pacote adotado para a arquitetura proposta

As configurações dos serviços de segurança selecionados no emissor da mensagem são adicionadas ao cabeçalho de configuração, que é parte do pacote de dados da arquitetura ilustrado na Figura 12. Assim, o receptor da mensagem é capaz de identificar qual foi o procedimento utilizado para processar a mesma e, por consequência, como deve proceder para processar a sua recepção, autenticando o pacote e/ou recuperando o texto claro. O cabeçalho de configuração é construído a partir da atribuição de valores aos seus bits de acordo com o protocolo especificado na Figura 13.

\begin{tabular}{|l|l|}
\hline Bits de configuração & Opções \\
\hline [0] Bit reservado & - \\
\hline [1] Configuração de confidencialidade & $0:$ cifração desabilitada \\
& $1:$ cifração habilitada \\
\hline [2:3] Configuração de autenticidade & $00:$ sem MAC \\
e integridade & $01:$ MAC de 64 bits \\
& $10:$ MAC de 96 bits \\
& $11:$ MAC de 128 bits \\
\hline [4:5] Comprimento do ID da chave de grupo & $00:$ sem ID de chave \\
& $01:$ ID de chave de 8 bits \\
& $10:$ ID de chave de 16 bits \\
& $11:$ ID de chave de 24 bits \\
\hline 6:7] Comprimento do contador & $00:$ sem segurança semântica \\
& $01:$ contador de 16 bits \\
& $10:$ contador de 24 bits \\
& $11:$ contador de 32 bits \\
\hline
\end{tabular}

Figura 13: Protocolo de construção do cabeçalho de configuração 
A arquitetura possui três diferentes níveis de segurança para o mecanismo de código de autenticação de mensagem, permitindo a seleção do comprimento do código autenticador para 64, 96 ou 128 bits. Esses valores seguem as recomendações do National Institute of Standards and Technology (NIST) (NIST, 2007), que reforça que o comprimento do código de autenticação de mensagem deve ser maior ou igual a 64 bits.

\begin{tabular}{|c|c|c|c|}
\hline $\begin{array}{c}\text { ENDEREÇO } \\
\text { DE ORIGEM }\end{array}$ & $\begin{array}{c}\text { ENDERECCO } \\
\text { DE DESTINO }\end{array}$ & $0^{*}$ & CONTADOR \\
\hline 2 BYTES & 2 BYTES & m bits & $0,2,3$ ou 4 BYTES \\
\hline
\end{tabular}

Figura 14: Vetor de inicialização

O vetor de inicialização do mecanismo de segurança semântica, ilustrado na Figura 14, é composto por: dois campos de endereço de rede (endereço de origem e endereço de destino) com 16 bits de comprimento cada um; um elemento de incremento de entropia com comprimento variável (0, 16, 24 ou 32 bits) nomeado contador; e um campo de $m$ bits de comprimento atribuídos com valor 0 , onde $m$ é determinado pela Equação 5.1.

$$
m=\mid \text { vetor de inicialização }|-32-| \text { contador } \mid
$$

Esses $m$ bits, atribuídos em 0, complementam o vetor de inicialização de acordo com o comprimento do contador selecionado (|contador $\mid)$ e com os requisitos de seu comprimento (|vetor de inicialização|) para o mecanismo de cifração. O valor 32 é referente à soma do comprimento dos campos de endereço de origem e endereço de destino.

Os campos de endereço de origem e endereço de destino podem reutilizar os repectivos dados da camada de rede, quando estes estiverem disponíveis para a camada de aplicação, evitando assim redundâncias. 
A adoção de comprimento variável para o campo contador foi uma decisão de projeto em prol da redução de informação a ser adicionada aos pacotes de dados. Desta forma, o overhead de comunicação pode ser tão pequeno quanto o possível, sendo o comprimento do contador incrementado conforme as necessidades do mecanismo de cifração.

Além disso, é possível utilizar o campo contador com comprimento zero, ou seja, o vetor de inicialização deixa de ter um elemento de incremento de entropia, ou um NONCE. A remoção do contador pode ser útil caso a aplicação apresente dados com alta entropia, permitindo assim uma maior redução do overhead de comunicação. Contudo, esta opção deve ser analisada com cautela, dado que sua utilização em uma aplicação de baixa entropia pode comprometer a segurança semântica dos dados transmitidos, dando subsídio a um atacante para inferir informações sobre os mesmos.

Por fim, a arquitetura também oferece a opção de adicionar a identificação da chave utilizada no processamento dos dados transmitidos. Quando o recurso é ativado, a identificação de chave é anexada ao pacote de dados da arquitetura, incorporada no campo id de chave, que tem tamanho variável $(0,1,2$ ou 3 bytes) como mostrado na Figura 12. Esse recurso permite a utilização de chaves criptográficas simétricas de grupos, isto é, possibilita a utilização de chaves compartilhadas dentro de determinados grupos, o que é útil para a comunicação multicast, ou nas rotinas de colaboração intragrupos como agregação de dados. Neste caso, a participação de um nó $x$ em um grupo $A$ é definida pela posse da chave criptográfica $K_{A}$, do grupo $A$, por este nó.

Um exemplo de utilização de chaves simétricas de grupos é ilustrado na Figura 15. Neste cenário, o nó sorvedouro, que conhece todas as chaves da rede, envia mensagens aos grupos $A$ e $B$ cifradas com a utilização de suas respectivas chaves criptográficas $\left(K_{A}\right.$ e $\left.K_{B}\right)$. Desta forma, apenas nós pertencentes a 
dado grupo, ou seja, que possuem a chave simétrica do grupo, podem ler as mensagens direcionadas a este. Os nós do grupo $C$, responsáveis por fazer o encaminhamento das mensagens, por exemplo, não são capazes de ler nenhuma das mensagens transmitidas neste exemplo, e os nós do grupo $A$ não conseguem ler as mensagens direcionadas ao grupo $B$ e vice-versa.

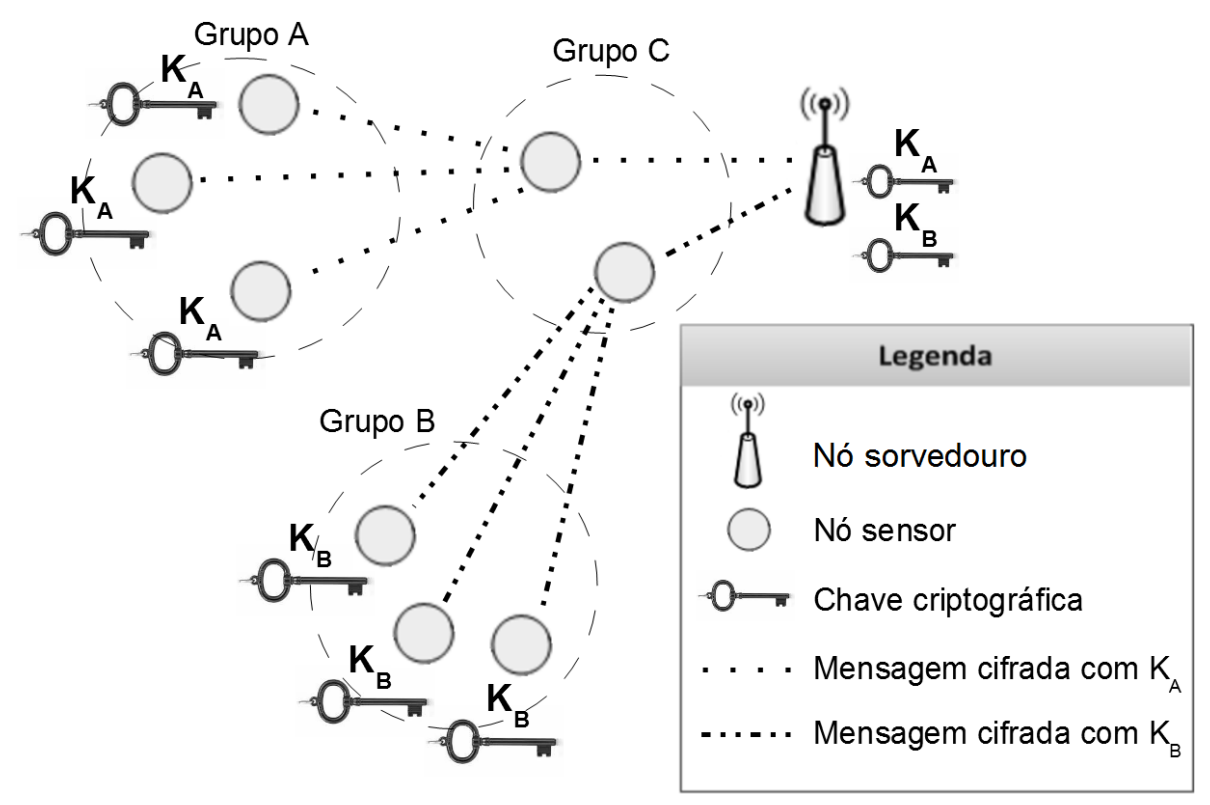

Figura 15: Exemplo de utilização de chaves simétricas de grupo

A utilização deste recurso possibilita a diminuição do trafego na rede e, consequentemente, a economia de energia. O nó sorvedouro, por exemplo, poderia enviar uma única mensagem, como uma requisição de tarefa, para um grupo inteiro com uma única transmissão, dado que a informação é cifrada com mesma chave. Isso não é possível quando a rede está trabalhando com uma chave para cada nó, pois os dados anexados na carga do pacotes (Figura 12) seriam diferentes para cada destinatário.

Contudo, esta abordagem também apresenta uma desvantagem, ela apresenta uma menor resiliência ao comprometimento de nós. De forma que, se algum nó da rede for comprometido, a segurança dos grupos aos quais este pertence é prontamente comprometida. 
Recomenda-se que o campo id de chave seja autenticado quando o serviço de autenticação estiver habilitado, permitindo assim a detecção de alterações neste campo. Também é importante ressaltar que este campo não pode ser cifrado, dado que o receptor da mensagem deve lê-lo prontamente.

\subsection{Análise de Algoritmos Candidatos à Imple- mentação da Arquitetura}

Nesta seção são analisados alguns algoritmos que implementam os mecanismos de segurança discutidos previamente. O principal objetivo desta análise é investigar quais algoritmos são mais adequados à implementação da prova de conceito da arquitetura proposta em relação às métricas consideradas.

Quatro algoritmos de código de autenticação de mensagem foram analisados neste trabalho. A seleção inclui três dos algoritmos mais comumente utilizados em aplicações modernas e um especificamente concebido para plataformas restritas: CMAC (NIST, 2005), PMAC (ROGAWAY, 2004), GMAC (NIST, 2007) e MARVIN (SIMPLICIO et al., 2009). Todos utilizam uma cifra de bloco subjacente, uma estratégia interessante e econômica, principalmente quando a plataforma possuir uma cifra de bloco disponível em seu hardware.

Também foram analisados quatro algoritmos de esquemas de cifração autenticada com dados associados: EAX (BELLARE; ROGAWAY; WAGNER, 2004), Galois/Counter Mode (GCM) (NIST, 2007), LETTERSouP (SIMPLICIO et al., 2009) e Offset CodeBook (OCB) (KROVETZ; ROGAWAY, 2005). Estes quatro algoritmos têm como base de segurança a cifra de bloco subjacente utilizada.

Para ambas as classes de algoritmos, código de autenticação de mensagem e cifração autenticada com dados associados, foi adotada como cifra de bloco subjacente o CURUPIRA-2 (SIMPLICIO et al., 2008), com chave de 96 bits e expansão 
de chave em tempo de execução (SIMPLICIO, 2009b). A escolha desta cifra se deu por esta ter sido projetada especificamente para dispositivos restritos, o que a priori resultaria em um menor impacto no desempenho, permitindo uma melhor análise comparativa dos algoritmos a qual esta foi acoplada.

\subsubsection{Metodologia de Avaliação de Desempenho e Uso de Memória}

Para a comparação dos algoritmos foi selecionada uma plataforma muito popular na área da pesquisa de RSSFs, o MEMSIC TelosB (MEMSIC, 2010c). Este dispositivo possui um microcontrolador MSP-430, que trabalha com uma frequência de ciclo de $8 \mathrm{MHz}$, e é provido de $48 \mathrm{KiB}$ de memória de código e $10 \mathrm{KiB}$ de memória volátil (ou $R A M)$.

As métricas consideradas na avaliação de desempenho são o consumo de energia e tempo de execução das operações criptográficas. Tais métricas tem o objetivo de verificar o impacto dessas operações considerando o overhead de processamento que implica em atrasos na comunicação e aumento do consumo de energia para a rede de sensor sem fio.

A abordagem de medição adotada neste trabalho é o mesmo método utilizado em Margi et al.(2010). A fim de obter uma medida exata do consumo de energia e do tempo de execução, foram realizadas medidas diretas sobre o sensor MEMSIC TelosB (MEMSIC, 2010c), executando o sistema operacional TinyOS (HILL et al., 2000) em sua versão 2.1.1. Foi utilizado o multímetro digital de alta precisão Agilent modelo 34401A (AGILENT, 2012a) para medir o fluxo de corrente, determinando assim quando o microcontrolador do sensor tornar-se ativo e inativo durante a execução dos testes, e uma fonte de alimentação precisa Agilent modelo E3631A (AGILENT, 2012b) configurado para fornecer $3 \mathrm{~V}$ de tensão ao sensor TelosB. 
A Figura 16 (a) mostra um diagrama que descreve a configuração do conjunto de equipamentos de medição: um cabo General Purpose Interface Bus (GPIB), padrão IEEE 488, utilizado para conectar o multímetro Agilent 34401A a um computador que executa o software LabView (NATIONAL INSTRUMENTS, 2012), versão 8.6, que coleta e armazena as amostras de medição.

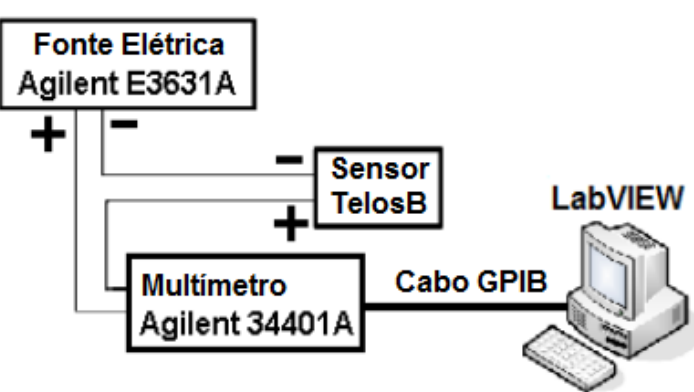

(a) Conjuto de Equipamentos de Medição

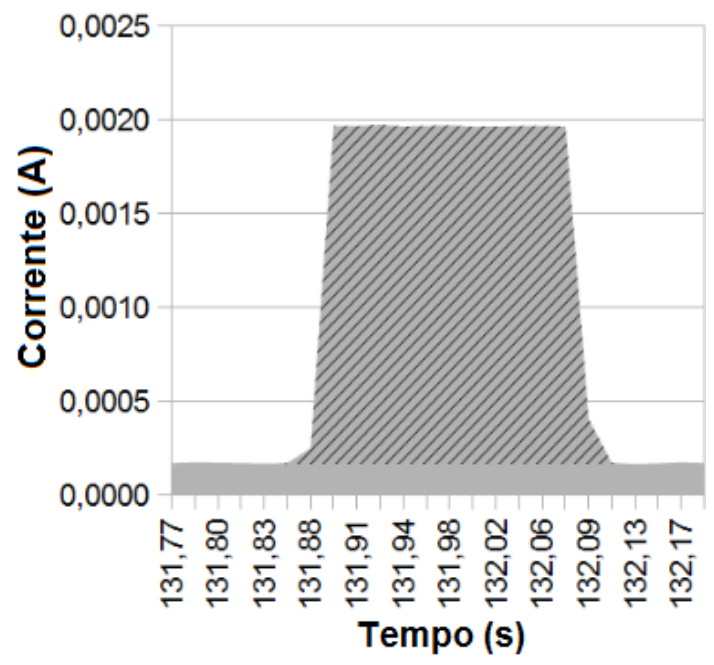

(b) Operação Capturada

Figura 16: Conjunto de equipamentos utilizado para análise de desempenho e exemplo de amostragem através do método de medição

Neste cenário de medição, primeiro é obtida a corrente drenada quando o sistema está em modo ocioso (idle), ou seja, nenhuma operação está sendo executada. Após isso, são obtidas medidas com operações sendo processadas. Então, a partir dos níveis de drenagem de correntes obtidos, é possível determinar quando o sistema está executando uma operação ou está em modo ocioso. A carga elétrica é obtida através da integração da curva corrente drenada x tempo, e prontamente, uma vez que a tensão elétrica é constante $(3 \mathrm{~V})$, obtém-se o consumo de energia de cada operação. A Figura 16 (b) mostra o gráfico de uma amostra de operação obtida pelo conjunto de medição: a área cinza lisa representa o consumo de energia do modo ocioso e na área hachurada representa o consumo do processamento. Assim, o tempo de execução é dada pela largura da área hachurada e a carga é 
dada pelo cálculo da sua área (ou integração da curva).

Para assegurar a identificação correta das operações, cada uma das execuções de operações foram separadas por intervalos de $5 \mathrm{~s}$ em modo ocioso. Após a medição foram realizados os cálculos descritos e a análise estatística dos resultados obtidos. Os resultados apresentados neste trabalho representam a média de 10 amostras adquiridas para cada configuração de operação.

As métricas de uso de memória consideradas são a ocupação da memória de código e a utilização da memória volátil (ou RAM), obtidas através das ferramentas MSP430-size e MSP430-ram-usage, repectivamente. Estas ferramentes são integradas ao compilador utilizado para gerar programas para o sensor TelosB, o MSP430GCC (UNDERWOOD, 2009).

\subsubsection{Resultados da Seleção dos Algoritmos}

Os níveis de tamanho de mensagem, fator adotado para esta avaliação de desempenho, são múltiplos de 12 bytes. Esses níveis foram selecionados de acordo com a cifra subjacente adotada, o CURUPIRA-2, que trabalha com blocos de 12 bytes.

Como é esperado, os resultados mostram que o consumo de energia dos algoritmos é proporcional ao seu tempo de execução, ou seja, quanto maior a demanda de tempo para um algoritmo ser executado, mais energia este consome.

Os resultados da análise de desempenho dos algoritmos de código de autenticação de mensagem estão contidos na Tabela 2. Os quais mostram que o GMAC apresentou o pior resultado entre os algoritmos analisados, sendo que os demais apresentaram resultados semelhantes entre eles.

A Figura 17 representa graficamente o desempenho dos três algoritmos mais eficientes. A partir desta representação é possível observar que o CMAC apresenta 
Tabela 2: Dados de desempenho dos algoritmos de código de autenticação de mensagem no sensor TelosB obtidos da média de 10 amostras para cada configuração

\begin{tabular}{l|ccc|ccc}
\hline \multirow{2}{*}{ Algoritmo } & \multicolumn{2}{|c|}{$\begin{array}{c}\text { Tempo de Execução }(\mathrm{ms}) \\
\text { [Desvio Padrão } \leqslant 0,1]\end{array}$} & \multicolumn{2}{c}{$\begin{array}{c}\text { Consumo de Energia }(\mu \mathrm{J}) \\
\text { [Desvio Padrão } \leqslant 0,01]\end{array}$} \\
\cline { 2 - 7 } & $\begin{array}{c}\text { Tamanho da mensagem } \\
\text { (bytes) }\end{array}$ & \multicolumn{3}{c}{$\begin{array}{c}\text { Tamanho da mensagem } \\
\text { (bytes) }\end{array}$} \\
& 12 & 24 & 36 & 12 & 24 & 36 \\
\hline CMAC & 1,3 & 2,5 & 3,7 & 6,66 & 13,24 & 19,88 \\
GMAC & 13,8 & 19,9 & 25,9 & 74,83 & 109,16 & 143,55 \\
MARVIN & 2,2 & 2,7 & 3,2 & 11,42 & 14,40 & 17,28 \\
PMAC & 1,8 & 3,2 & 4,1 & 7,18 & 13,95 & 20,77 \\
\hline
\end{tabular}

melhor desempenho para mensagens de tamanho pequeno, menor que dois blocos da cifra de bloco subjacente, 24 bytes neste caso. Contudo, a partir de dois blocos de comprimento o MARVIN apresenta um melhor desempenho, confirmando a tendência de melhora em relação ao CMAC que pode ser observada entre 12 e 24 bytes. O PMAC não apresentou melhor desempenho para nenhum dos casos de teste.

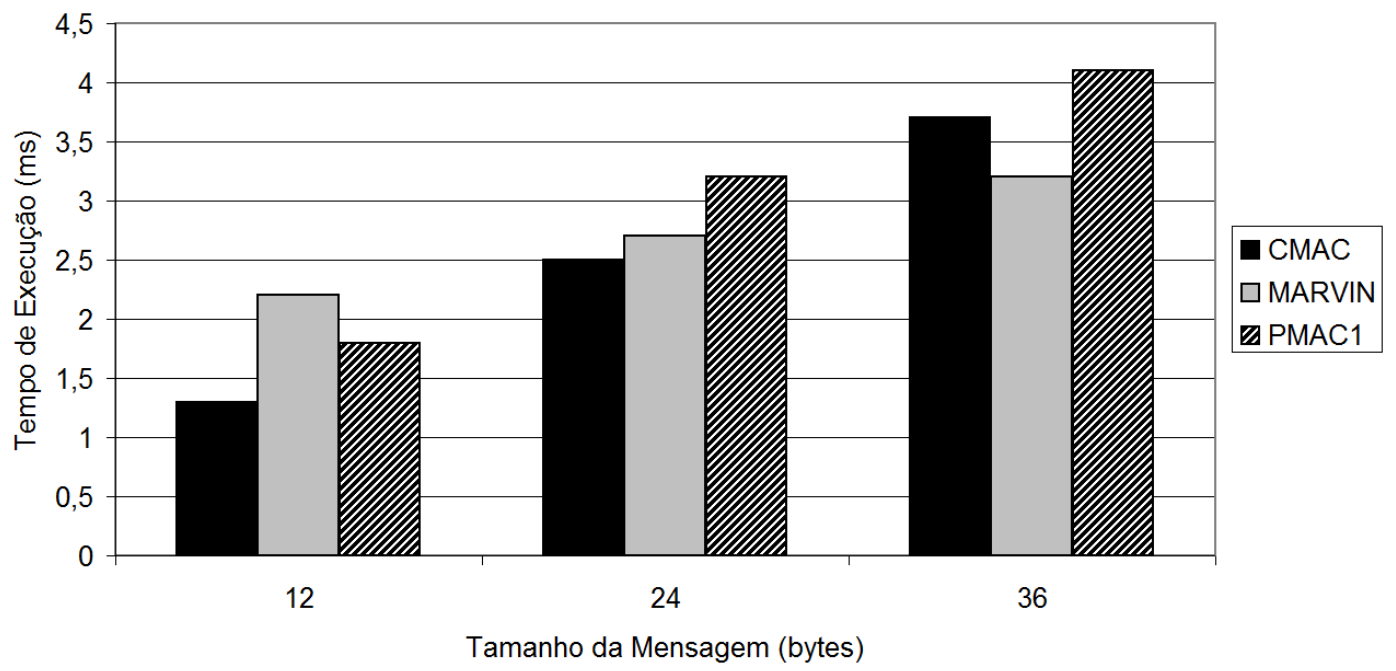

Figura 17: Representação gráfica do desempenho dos algoritmos de código de autenticação de mensagem

Em relação ao uso de memória, os resultados contidos na Tabela 3 mostram que o MARVIN ocupou aproximadamente 4,5\% menos memória de código que o segundo melhor neste requisito, o PMAC. Entretanto, o PMAC utilizou apro- 
ximadamente 5,4\% menos memória volátil $(R A M)$ que o MARvin, que utilizou a mesma quantidade que o GMAC. O CMAC apresentou maior ocupação de memória para as duas métricas.

Tabela 3: Dados do uso de memória dos algoritmos de código de autenticação de mensagem no sensor TelosB obtidos através das ferramentas MSP430-size e MSP430-ram-usage

\begin{tabular}{lcc}
\hline Algoritmo & Código (bytes) & RAM (bytes) \\
\hline CMAC & 3030 & 152 \\
GMAC & 2930 & 148 \\
PMAC & 2912 & 140 \\
MARVIN & 2784 & 148 \\
\hline
\end{tabular}

O MARVin e o CMAC apresentaram resultados competitivos em relação ao desempenho, sendo que cada qual mostrou-se mais eficiente para tamanhos de mensagens diferentes. Considerando o uso da memória, o MARvin apresentou bons resultados, sendo competitivo em relação ao PMAC, que apresentou resultado um pouco melhor para o uso de RAM. Assim, é possível afirma que o MARVIN é o algoritmo que apresentou os resultados mais equilibrados entre os algoritmos analisados.

Para os algoritmos de cifração autenticada com dados associados foi executado um conjunto maior de testes de desempenho, utilizando um número maior de níveis para o fator tamanho de mensagem, por conta de sua maior complexidade e variabilidades dos argumentos de entrada de suas funções. Assim, foram executadas operações de cifração com autenticação utilizando mensagens de 12 , 24, 36, 48 e 60 bytes; e dados associados $(D A)$ de 0,12 ou 24 bytes. Os resultados dos referidos testes são apresentados na Tabela 4 .

Ao observar a Tabela 4 é possível identificar que o algoritmo GCM apresenta desempenho bem inferior aos outros três algoritmos para todas as cargas de trabalho testadas. Se comparado ao EAX, por exemplo, o GCM é três vezes menos eficiente. Os algoritmos EAX, LETTERSOUp e OCB apresentaram vantagens 
Tabela 4: Dados de desempenho dos algoritmos de cifração autenticada com dados associados no sensor TelosB obtidos da média de 10 amostras para cada configuração

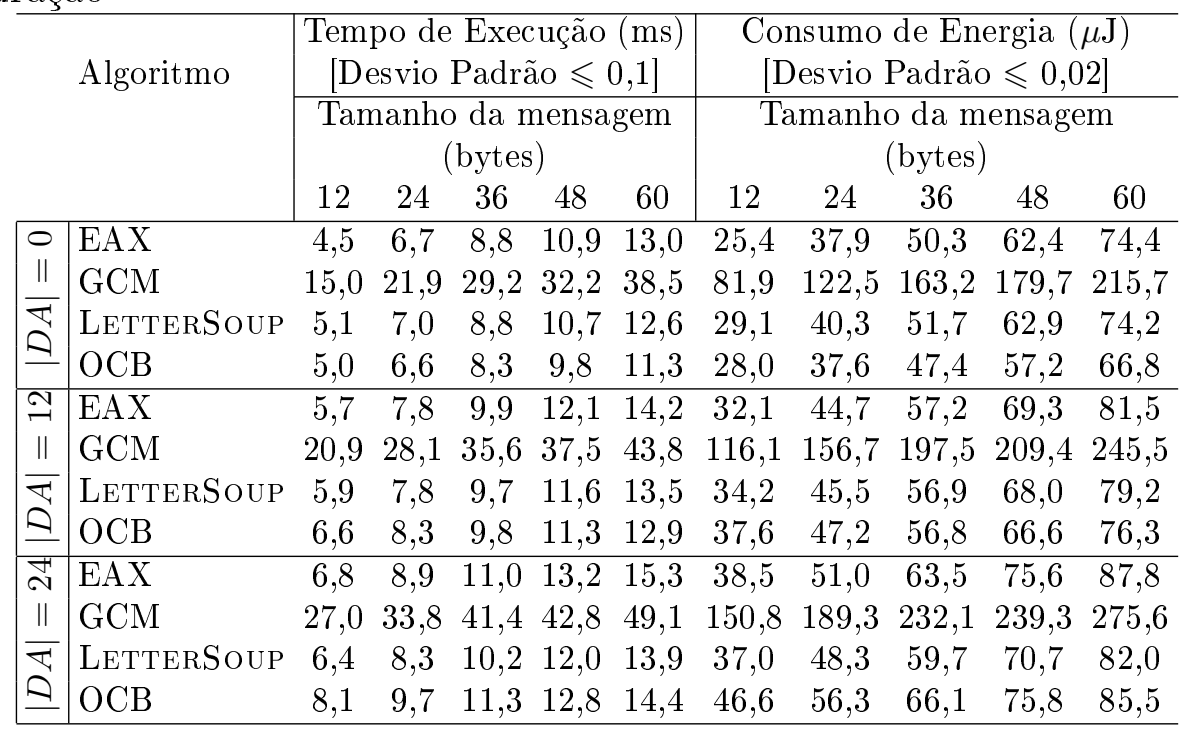

para diferentes cargas de trabalho. Ao observar a Figura 18, na qual é apresentado um gráfico de tempo de execução dos referidos algoritmos, nota-se que o EAX apresentou melhor desempenho para mensagens menores (12 bytes). Já o OCB mostrou-se a melhor opção para as mensagens maiores, e o LETTERSOUP passa a ser competitivo para mensagens de tamanho intermediário quando dados $\operatorname{associados}(D A)$ são adicionados.

A métrica de uso de memória dos algoritmos de cifração autenticada com dados associados, apresentados na Tabela 5, resultou em dados que indicam melhor eficiência do LeTterSoup , que ocupou menos memória de código e apresentou a segunda menor utilização de memória volátil. O algoritmos OCB utilizou aproximadamente $1 \%$ menos memória volátil que o LETTERSOUP, mas ocupou cerca de $28 \%$ memória de código a mais. O EAX e o GCM não apresentaram resultados comparativamente favorecedores para nenhuma das duas métricas de uso de memória.

Como para as métricas de desempenho três algoritmos apresentaram resultados equilibrados, e o LETTERSOUP apresentou vantagem em relação ao OCB 

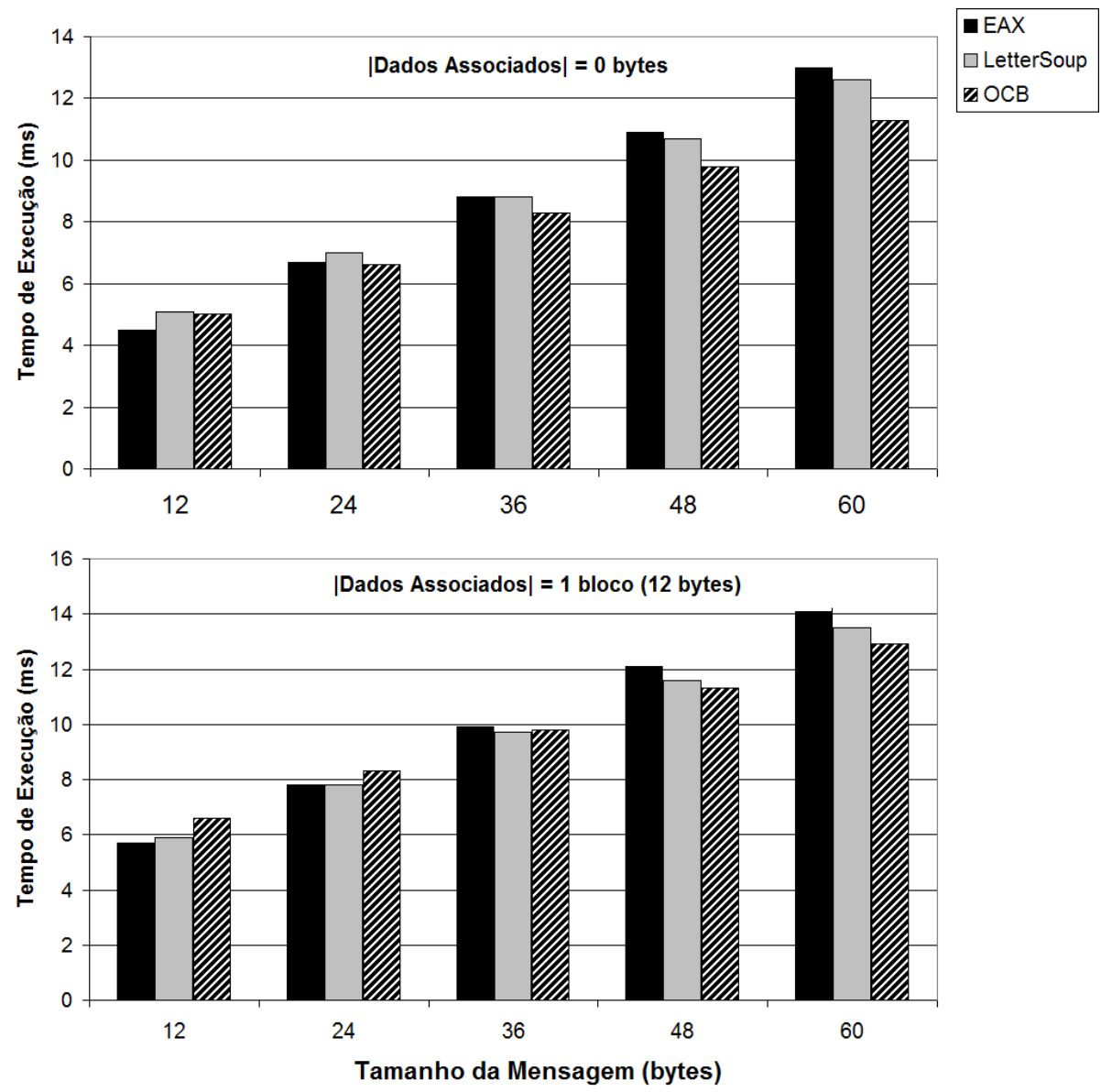

Figura 18: Tempo de execução dos algoritmos de cifração autenticada com dados associados

em relação ao uso de memória, o LETTERSoup foi selecionado para a implementação da arquitetura. A característica de apresentar um bom desempenho com dados associados, também foi uma vantagem considerada para a seleção do LETTERSOuP, dado que a arquitetura utilizará o campo id de chave como dado associado quando a cifração estiver ativada.

\subsection{Implementação da Arquitetura para Prova de Conceito}

O objetivo da implementação apresentada nesta seção é estabelecer uma plataforma de teste para validar o projeto da arquitetura de segurança, bem como testar sua viabilidade de implantação em RSSFs. Contudo, a arquitetura de 
Tabela 5: Dados do uso de memória dos algoritmos de cifração autenticada com dados associados no sensor TelosB obtidos através das ferramentas MSP430-size e MSP430-ram-usage

\begin{tabular}{lcc}
\hline Algoritmo & Código (bytes) & RAM (bytes) \\
\hline OCB & 5120 & 216 \\
EAX & 4528 & 252 \\
GCM & 3862 & 220 \\
LETTERSOUP & 3682 & 218 \\
\hline
\end{tabular}

segurança não é limitada a esta implementação e nem atrelada aos algoritmos utilizados, sendo possível efetuar modificações nesta para a utilização de outros algoritmos que implementem os mesmo mecanismos e, consequentemente, os mesmos serviços de segurança. Assim como a abordagem adotada em Bandirmali e Erturk (2012), é possível utilizar uma cifra subjacente de bloco de menor comprimento com o objetivo de melhorar o desempenho em relação a processamento.

De acordo com a análise apresentada neste capítulo, os algoritmos utilizados para a implementação da arquitetura foram: o MARVIN, como algoritmo de código de autenticação de mensagem, utilizado no modo de funcionamento autenticação; e o LETTERSOUP , como algoritmo de cifração autenticada com dados associados, utilizado no modo de funcionamento cifração autenticada.

Para o modo somente cifração, inicialmente foi utilizado o LETTERSoup ignorando o código autenticador gerado pelo algoritmo, resultando assim em um overhead de processamento inútil, dado que a execução de autenticação não é requerida neste modo de funcionamento. Oportunamente, o LETTERSoup incorpora em sua estrutura o modo de operação Linear Feedback Shift Register Counter (LFSRc) (KRAWCZYK, 1994), que executa somente cifração. Desta forma, a partir da implementação do LeTterSoup contida em Simplicio (2009a) foram executadas alterações para que o processamento da autenticação seja interrompido quando não houver necessidade de geração do código autenticador.

Em relação à segurança semântica, o LETTERSoup apresenta apenas duas 
restrições para a utilização do vetor de inicialização, este não pode se repetir para a utilização de uma mesma chave e não pode ser um vetor cujos todos seus bits sejam atribuídos como 0. Desta forma, a variação do vetor de inicialização é executada a partir da utilização de um contador monotônico crescente adicionado no campo contador, complementando assim o vetor de inicialização especificado na Figura 14).

$\mathrm{Na}$ implementação foram incluídas duas opções de cifra subjacente a serem utilizadas nas estruturas do LETTERSOUP, do LFSRc e do MARVIN: o Curupira-2 e o Advanced Encryption Standard (AES) (DAEMEN; RIJMEN, 2000), uma cifra presente em diversos padrões, como no padrão IEEE 802.15.4 (IEEE, 2006), e também nas arquiteturas de segurança Minisec (LUK et al., 2007) e ContikiSec (DUNKELS; GRONVALL; VOIGT, 2004). A versão do AES adotada foi a AES-128, que trabalha com blocos de 128 bits (ou 16 bytes).

Para o desenvolvimento da implementação da arquitetura, houve a preocupação em escrever e adaptar os códigos de uma forma genérica, utilizando o padrão ANSI $C^{1}$, com o objetivo de possibilitar a compilação da mesma para uma grande variedade de plataformas, permitindo estabelecer a interoperabilidade entre diferentes sistemas e dispositivos.

Após o seu desenvolvimento, a implementação foi testada em computadores pessoais com sistema operacional Linux e na plataforma TelosB (MEMSIC, 2010c) utilizando o sistema operacional TinyOS (HILL et al., 2000) na sua versão 2.1.

O TinyOS e suas aplicações são escritos em NesC (GAY et al., 2003), uma linguagem derivada da linguagem $\mathrm{C}$ que tem como foco sistemas embarcados de redes e que permite a programação orientada a eventos. Contudo, em NesC é possível importar bibliotecas escritas em ANSI C e utilizar suas funções, o que

\footnotetext{
${ }^{1}$ ANSI C refere-se à família de normas sucessivas, publicados pela American National Standards Institute (ANSI) para a linguagem de programação C.
} 
torna a implementação da arquitetura proposta compatível com o TinyOS.

O código-fonte da implementação, bem como a documentação que descreve os requisitos, recomendações e instruções de uso, incluindo exemplos de aplicações, estão disponíveis no site da ferramenta WSN-ETESec (OLIVEIRA; MARGI, 2012b). 


\section{AVALIAÇÃO DA ARQUITETURA PROPOSTA}

Neste capítulo é avaliada a arquitetura proposta utilizando métricas quantitativas e qualitativas. A Seção 6.1 contém a avaliação de desempenho da implementação da arquitetura, e na Seção 6.2 é apresentada uma avaliação qualitativa da arquitetura em relação aos requisitos considerados previamente.

\subsection{Desempenho da Implementação da Arquite- tura}

Esta avaliação de desempenho considera as métricas de tempo de processamento e consumo de energia das operações executadas pelos modos de funcionamento da arquitetura proposta no presente trabalho. Para a coleta e análise dos dados referente às métricas consideradas foi aplicado o mesmo método utilizado e descrito na Seção 5.3.1. Para os testes que geraram os resultados contidos nesta seção foi considerada apenas a cifra de bloco subjacente AES, pois já foram apresentados resultados com o Curupira-2 e a priori os resultados seriam os mesmos ou muito parecidos. Os níveis do fator tamanho de mensagem são múltiplos de 16 bytes, tamanho de bloco utilizado pela cifra de bloco AES.

A Tabela 6 apresenta os resultados das medidas de tempo de execução e consumo de energia para os modos de funcionamento: somente cifração (operações de cifração e decifração), autenticação (operação de geração do código autentica- 
dor) e cifração autenticada (operações de cifração e decifração com autenticação). O modo de funcionamento sem segurança não resulta em overhead de processamento e de consumo de energia significativos, pois a única operação que o modo executa é a leitura do cabeçalho de configuração, por esta razão o mesmo não está presente na referida tabela.

Tabela 6: Dados de desempenho dos modos de funcionamento no sensor TelosB obtidos da média de 10 amostras para cada configuração

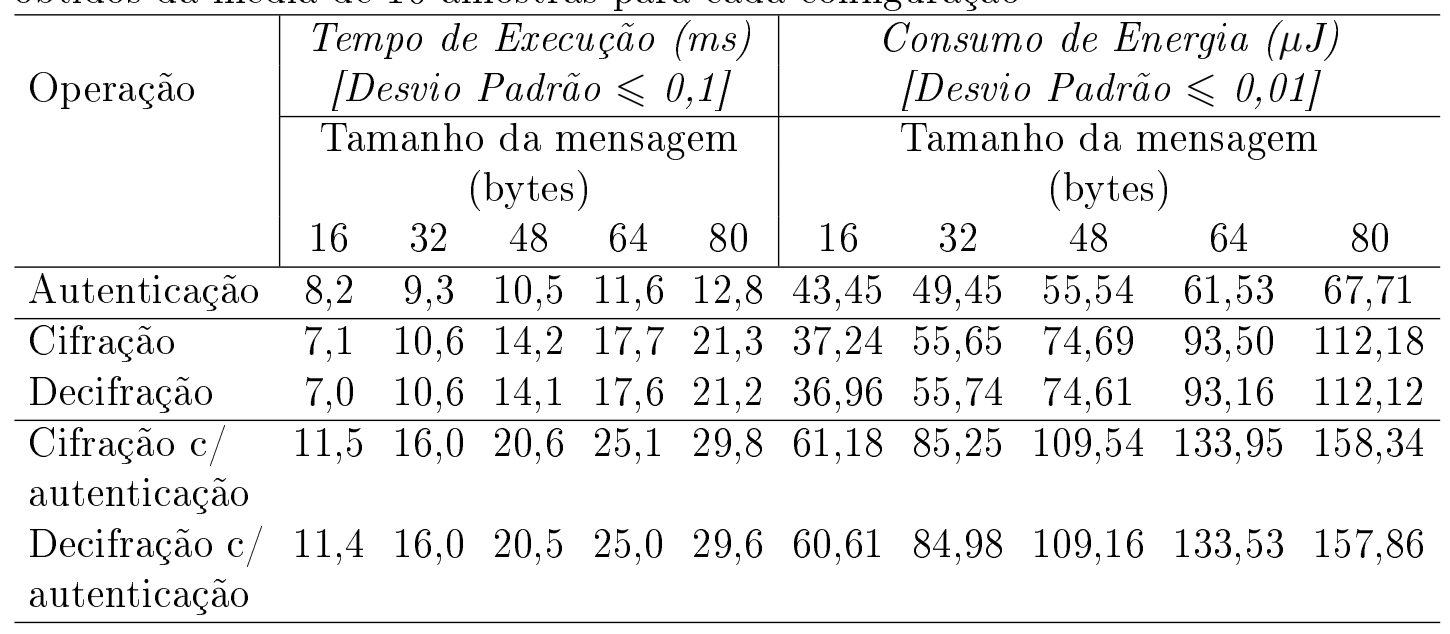

Nota-se que as operações de cifração e decifração apresentam resultados muito parecidos, tanto para o modo somente cifração quanto para o modo cifração autenticada, ou seja, o overhead de processamento é praticamento o mesmo para os nós emissor (que executa autenticação, cifração e cifração com autenticação) e receptor (que executa autenticação, decifração e decifração com autenticação).

Em relação a diferença de desempenho entre os modos de funcionamento, a partir da representação gráfica contida na Figura 19, que mostra o tempo das operações executadas no nó emissor, é possível observar que para mensagens pequenas (menores ou igual a 16 bytes) o modo de somente cifração é mais rápido que o modo de autenticação, mas isto se reverte para mensagens maiores. Isso ocorre porque o algoritmo de código de autenticação de mensagem adotado na implementação, o MARVIN, utiliza a cifra de bloco subjacente apenas duas vezes durante a geração do código autenticador. Já os algoritmos que envolvem 
cifração precisam acessar a cifra de bloco subjacente a cada bloco processado da mensagem.

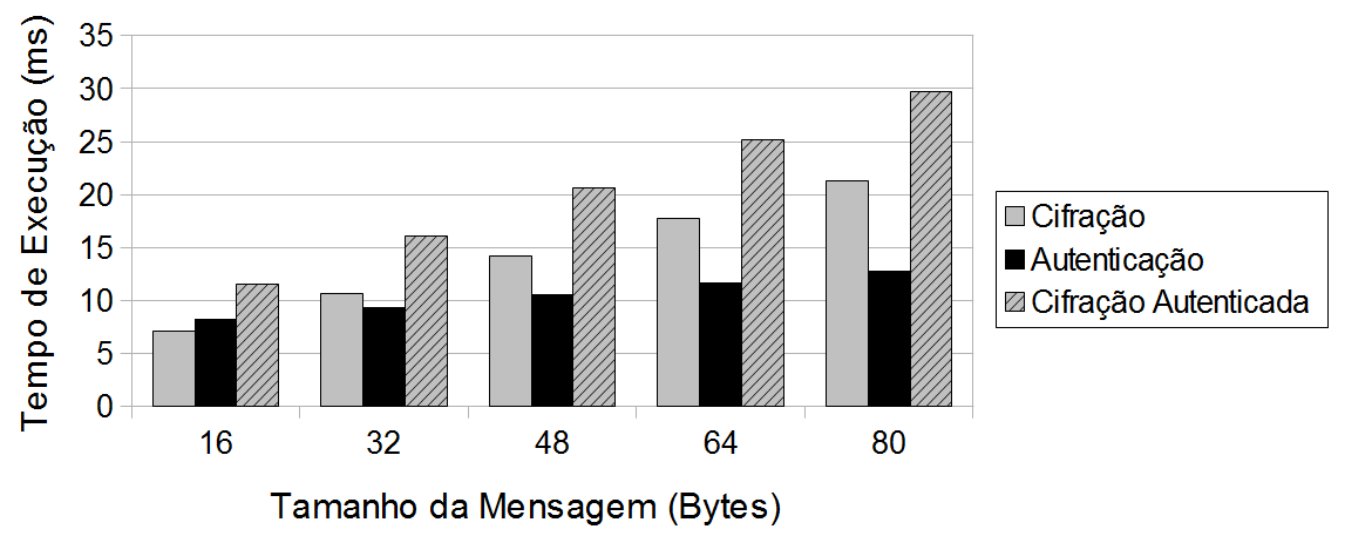

Figura 19: Gráfico do tempo de execução das operações dos modos de funcionamento

Além disso, observa-se que o modo cifração autenticada apresenta menor tempo de execução que a soma de tempo de execução dos dois outros modos apesar de prover os mesmos serviços de segurança da união destes dois. Por exemplo, para uma mensagem de 64 bytes os modos somente cifração e autenticação levam mais que $20 \mathrm{~ms}$ e $10 \mathrm{~ms}$ para serem executados, respectivamente, mas o modo cifração autenticada tem sua execução completa antes de $30 \mathrm{~ms}$. Desta forma, fica explícita a vantagem de utilizar um algoritmo de cifração autenticada com dados associados, o LeTterSoup no caso. Isso ocorre porque o LETTERSOUP utiliza alguns resultados intermediários da cifração para o calculo do código de autenticação, reduzindo o número de processamentos pela cifra de bloco.

A Figura 20, que é a representação gráfica dos dados de consumo de energia apresentados na Tabela 6, mostra a tendência de crescimento do consumo de energia para cada um dos modos de funcionamento em relação ao aumento do tamanho das mensagens. A partir deste gráfico é possível notar que o modo de cifração autenticada tem um crescimento de consumo de energia mais acentuado de acordo com o aumento dos tamanhos das mensagens, seguido pelo modo de somente cifração, que apresenta um crescimento um pouco menos acentuado; e 
pelo modo de autenticação, que possui um crescimento bem atenuado.

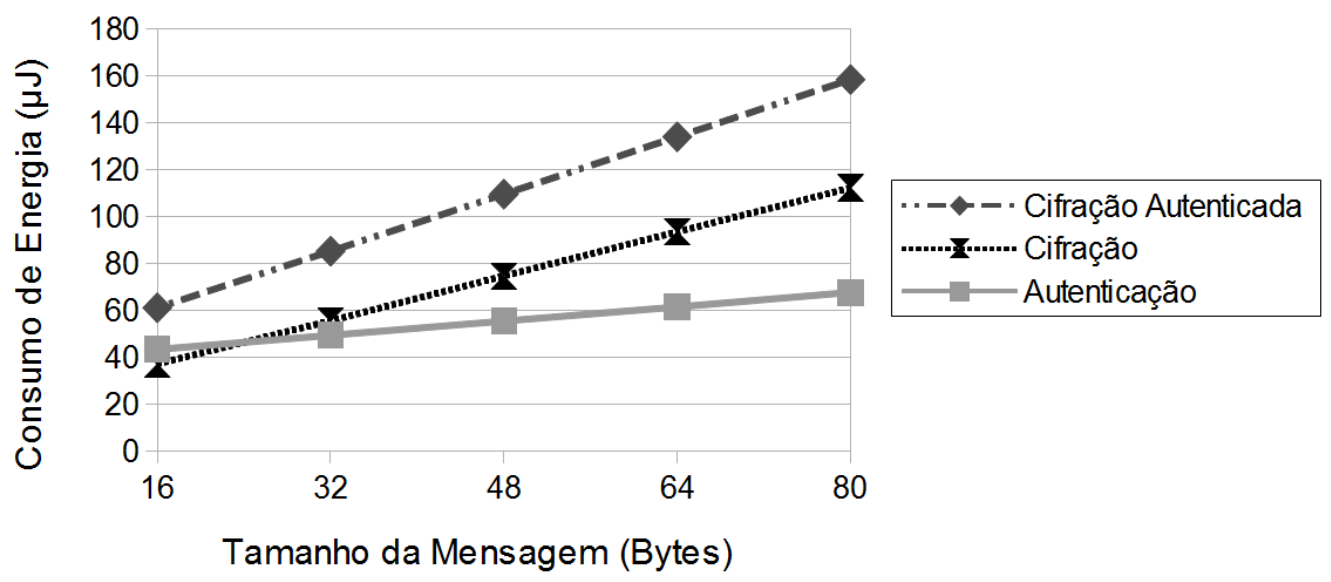

Figura 20: Gráfico do consumo de energia das operações dos modos de funcionamento

Isso significa que o modo autenticação sofre um menor impacto com o aumento do tamanho das mensagens. Contudo, o crescimento do consumo do energia para os três modos analisados é linear e tem coeficiente menor que 1, ou seja, quão maior é a mensagem, menor o custo energético por byte processado.

É importante ressaltar que os resultados apresentados nesta seção são referentes a implementação aqui discutida como prova de conceito, e que uma outra abordagem de implementação da arquitetura proposta neste trabalho, utilizando outros algoritmos ou mecanismos, pode apresentar resultados distintos.

\subsection{Avaliação da Especificação}

A partir da implementação apresentada na Seção 5.4 e dos resultados de testes apresentados na Seção 6.1 foi possível validar a especificação da arquitetura de segurança proposta. Esta implementação foi construída de forma desacoplada do sistema operacional, trata-se de uma biblioteca escrita para atuar na camada de aplicação, que o programador deve importar na função principal de sua aplicação utilizando suas funções para processar as mensagens a serem enviadas e as recebidas. Assim, é possível estabelecer a interoperabilidade de segurança en- 
tre diferentes sistemas e plataformas de hardware, dado que a implementação foi escrita em uma linguagem de programação compilável para diversas plataformas.

O uso implementação da arquitetura, concebida como prova de conceito da especificação, facilita a criação de aplicações seguras, dado que o programador das aplicações para RSSFs precisa apenas aprender a utilizar as interfaces das funções de processamento de mensagens, anulando a necessidade de um conhecimento específico por parte dele. Esta abordagem apresenta uma pequena desvantagem em relação às arquiteturas de segurança projetadas para camada de enlace, dado que para estas, o programador precisa apenas ativar o recurso de segurança e atribuir a chave criptográfica a ser utilizada, tornando o processamento das mensagens transparente aos desenvolvedores.

Outra vantagem da especificação apresentada em relação as demais arquiteturas analisadas neste trabalho, é o contador (parte do vetor de inicialização utilizado para segurança semântica) de tamanho variável. Desta forma, é possível utilizar um contador de comprimento tão pequeno quanto possível e expandi-lo quando necessário, diminuindo o overhead de comunicação e prolongando o uso das chaves criptográficas, desde que o estouro do contator implica na necessidade de troca da chave utilizada, um processo muito custoso.

Por fim, outra vantagem da abordagem utilizada no desenvolvimento desta arquitetura é a possibilidade do uso da segurança fim-a-fim para prover um canal seguro para um esquema arbitrado de distribuição de chaves criptográficas, facilitando a implementação desta de abordagem. 


\section{CONSIDERAÇÕES FINAIS}

Neste trabalho foi apresentado o desenvolvimento de uma arquitetura de segurança fim-a-fim para RSSFs, que incluiu especificação, implementação e validação.

A arquitetura proposta foi projetada para atuar na camada de aplicação da rede, permitindo assim a interoperabilidade dos serviços de segurança entre diferentes sistemas, dado que esta não está atrelada a nenhum sistema operacional ou dispositivo específico.

A implementação foi feita a partir da seleção de algoritmos de criptografia que incluiu análise de desempenho, considerando tempo de execução e consumo de energia, e testes de uso de memória. Na implementação tomou-se o cuidado de utilizar o padrão da linguagem C compatível com diversas plataformas.

O projeto da arquitetura e sua implementação permitem a ativação e desativação dos serviços de segurança em tempo de execução, possibilitando minimizar a utilização de recursos da rede de acordo com suas necessidade, que podem variar no decorrer do tempo de vida da mesma.

A validação da arquitetura foi feita a partir de sua implementação e avaliação de desempenho dos seus modos de funcionamento em uma plataforma de RSSFs. Além disso, sua especificação e implementação foram apresentadas à comunidade de pesquisa em redes de computadores como descrito no Apêndice A. 


\subsection{Trabalhos Futuros}

Como indicação de pesquisas futuras, destaca-se a implementação da arquitetura proposta em camada de enlace da pilha de protocolos de rede, permitindo a esta trabalhar como um mecanismo de segurança cross-layer, ou seja, atuante em mais de uma camada. A partir deste desenvolvimento, os algoritmos instanciados na camada de aplicação poderiam ser utilizados na camada de enlace provendo segurança a salto-a-salto e fim-a-fim, além de economizar memória dado que os mecanismos seriam compartilhados entre as camadas, eliminando a necessidade de adicionar mais de uma instância de mecanismos de segurança no dispositivo.

Outra atividade relevante para trabalhos futuros seria o desenvolvimento de um estudo com objetivo de estender o escopo da arquitetura para o modelo da Internet das Coisas, analisando as implicações desta ampliação de escopo. Este novo escopo envolveria uma maior complexidade, dado que tratam-se de redes híbridas, com enlaces de diferentes características, velocidades e disponibilidades de conexões, e que são compostas por dispositivos de diferentes recursos e poder computacional variado. Sendo assim, seria necessário também analisar o desempenho da arquitetura de segurança em diversas plataformas, como diferentes tipos de sensores sem fio, telefones celulares, kits de prototipagem e outros dispositivos candidatos a interagir com as RSSFs. 


\section{REFERÊNCIAS}

AGILENT. Agilent 34401A Multimeter Uncompromising Performance for Benchtop and System Testing - Data Sheet. Santa Clara - CA: Agilent Technologies, Inc., 2012. Disponível em: <http://cp.literature.agilent.com/ litweb/pdf/5968-0162EN .pdf>. Acesso em: 31 de agosto de 2012.

Agilent E3631A Triple Output DC Power Supply. Santa Clara - CA: Agilent Technologies, Inc., 2012. Disponível em: <http://cp.literature. agilent.com/litweb/pdf/E3631-90002.pdf $>$. Acesso em: 31 de agosto de 2012 .

AMARO, G. Criptografia simétrica e criptografia de chaves públicas: vantagens e desvantagens. Revista Negócios e Tecnologia da Informação, v. 2, n. 1, p. 84-94, 2007.

ARANHA, D. F.; OLIVEIRA, L. B.; LÓPEZ, J.; DAHAB, R. NanoPBC: implementing cryptographic pairings on an 8-bit platform. In: Conference on $\mathrm{Hy}$ perelliptic curves, discrete Logarithms, Encryption, etc (CHiLE 2009). Frutillar: [s.n.], 2009.

BANDIRMALI, N.; ERTURK, I. WSNSec: A scalable data link layer security protocol for wsns. Ad Hoc Networks, Elsevier, Boston, MA, v. 10, n. 1, p. 37-45, 2012. ISSN 1570-8705. Disponível em: <http://www.sciencedirect.com/science/article/pii/S157087051100103X>.

BELLARE, M.; ROGAWAY, P.; WAGNER, D. The EAX mode of operation: A two-pass authenticated-encryption scheme optimized for simplicity and efficiency. In: Fast Software Encryption 2004. Nova Iorque, NY: Springer-Verlag, 2004. (Lecture Notes in Computer Science, v. 3017), p. 389-407. http://www . cs.ucdavis.edu/ rogaway/papers/eax.pdf.

BIHAM, E.; BIRYUKOV, A.; SHAMIR, A. Cryptanalysis of skipjack reduced to 31 rounds using impossible differentials. In: . Nova Iorque, NY: Springer-Verlag, 1999. p. $12-23$.

BISHOP, M. Computer Security: Art and Science. Boston, MA: Addison-Wesley, 2003.

CARMAN, D. W.; KRUUS, P. S.; MATT, B. J. Constraints and approaches for distributed sensor network security. Glenwood, MD, set. 2000. v. 00, n. 010. Disponível em: <http://www.cs.umbc.edu/courses/graduate/CMSC691A/ Spring04/papers/nailabs_report_00-010_final.pdf $>$. Acesso em: 31 de agosto de 2012 . 
CASADO, L.; TSIGAS, P. Contikisec: A secure network layer for wireless sensor networks under the contiki operating system. Proceedings of the 14th Nordic Conference on Secure IT Systems (NordSec 2009), Lecture Notes in Computer Science, v. 5838, s. 133-147, 2009.

CULLER, D.; ESTRIN, D.; SRIVASTAVA, M. Overview of sensor networks. Computer Magazine, IEEE Computer Society, Washington, DC, v. 37, n. 8, p. 41-49, 2004.

DAEMEN, J.; RIJMEN, V. The block cipher rijndael. In: CARDIS '98: Proceedings of the The International Conference on Smart Card Research and Applications. Londres, UK: Springer-Verlag London Limited, 2000. p. 277-284. ISBN 3-540-67923-5.

DUNKELS, A.; GRONVALL, B.; VOIGT, T. Contiki - a lightweight and flexible operating system for tiny networked sensors. In: $L C N$ '04: Proceedings of the 29th Annual IEEE International Conference on Local Computer Networks. Washington, DC: IEEE Computer Society, 2004. p. 455-462. ISBN 0-7695-2260-2.

ESCHENAUER, L.; GLIGOR, V. D. A key-management scheme for distributed sensor networks. In: $C C S$ '02: Proceedings of the 9th ACM conference on Computer and communications security. Nova Iorque, NY: ACM Press, 2002. p. $41-47$.

FIPS. Data encryption standard. In: In FIPS PUB 46, Federal Information Processing Standards Publication. Gaithersburg, MD: The National Institute of Standards and Technology, 1977. p. 46-2.

GAY, D.; WELSH, M.; LEVIS, P.; BREWER, E.; BEHREN, R. von; CULLER, D. The nesC language: A holistic approach to networked embedded systems. In: Proceedings of Programming Language Design and Implementation. San Diego, USA: ACM, New York, USA, 2003. p. 1-11.

HILL, J.; SZEWCZYK, R.; WOO, A.; HOLLAR, S.; CULLER, D.; PISTER, K. System architecture directions for networked sensors. SIGPLAN Notices, ACM, Nova Iorque, NY, v. 35, n. 11, p. 93-104, 2000. ISSN 0362-1340.

HONG, Y.-W. P.; WANG, S.-H.; LIN, C.-K.; CHANG, B.-Y. Wireless sensor networks: Signal processing and communications perspectives (edited book). John-Wiley \& Sons, 2007.

IEEE. IEEE Standard for Wireless LAN Medium Access Control (MAC) and Physical Layer (PHY) Specifications. Piscataway, NJ, Nov 1997. P802.11.

. IEEE 802.15.4: Wireless medium access control (MAC) and physical layer $\overline{(P H Y)}$ specifications for low-rate wireless personal area networks (WPANs). Piscataway, NJ, 2006. P802.15.4.

JINWALA, D.; PATEL, D.; DASGUPTA, K. Flexisec: A configurable link layer security architecture for wireless sensor networks. Journal of Information Assurance \&f Security, Dynamic Publishers, v. 4, n. 6, p. 582-603, 2009. 
KARLOF, C.; SASTRY, N.; WAGNER, D. Tinysec: a link layer security architecture for wireless sensor networks. In: SenSys '04: Proceedings of the 2nd international conference on Embedded networked sensor systems. Nova Iorque, NY: ACM, 2004. p. 162-175. ISBN 1-58113-879-2.

KRAWCZYK, H. LFSR-based hashing and authentication. In: Advances in Cryptology - Crypto'94. Heidelberg, Germany: Springer, 1994. (Lecture Notes in Computer Science, v. 839), p. 129-139. ISBN 3-540-58333-5.

KROVETZ, T.; ROGAWAY, P. Internet Draft: The OCB AuthenticatedEncryption Algorithm. March 2005. http://www.cs.ucdavis.edu/〜rogaway/ papers/ocb-id.htm.

LUK, M.; MEZZOUR, G.; PERRIG, A.; GLIGOR, V. MiniSec: a secure sensor network communication architecture. In: IPSN '0\%: Proceedings of the 6th international conference on Information processing in sensor networks. Nova Iorque, NY: ACM, 2007. p. 479-488. ISBN 978-1-59593-638-X.

MAIA, R. J. M.; BARRETO, P. S. L. M.; OLIVEIRA, B. T. de. Implementation of multivariate quadratic quasigroup for wireless sensor network. Transactions on Computational Science, Springer, v. 11, p. 64-78, 2010.

MARGI, C. B. Energy Consumption Trade-offs in Power Constrained Networks. Tese (Doutorado) - University of California Santa Cruz, 2006.

MARGI, C. B.; OLIVEIRA, B. T. de; SOUSA, G. T. de; JR, M. A. S.; BARRETO, P. S. L. M.; CARVALHO, T. C. M. B.; NASLUND, M.; GOLD, R. Impact of operating systems on wireless sensor networks (security) applications and testbeds. In: . Piscataway, NJ: The Institute of Electrical and Electronics Engineers, 2010. p. 1 -6. ISSN 1095-2055.

MARGi, C. B.; SimpliCiO, M. A.; BARRETO, P. S. L. M.; CARVAlho, T. C. M. B. Segurança em redes de sensores sem fio. In: Minicursos: SBSEG 2009 / IX Simpósio Brasileiro de Segurança da Informação e de Sistemas Computacionais. 1. ed. Porto Alegre, RS: Sociedade Brasileira de Computação, 2009. p. 149 - 194.

MEMSIC. MICAz Datasheet. Andover, MA: MEMSIC Inc., 2010. Disponível em: <http://www.memsic.com/support/documentation/wireless-sensornetworks/category/7-datasheets.html?download=148\%3Amicaz $>$. Acesso em: 31 de agosto de 2012.

. $\bar{e}$ Ko Outdoor Wireless System For Enviromental Monitoring. Andover, MA: MEMSIC Inc., 2010. Disponível em: <http://www.memsic.com/support/ documentation/eko/category/15-datasheets . html?download=156\%3Aekobase-station $>$. Acesso em: 31 de agosto de 2012.

- TelosB Datasheet. Andover, MA: MEMSIC Inc., 2010. Disponível em: <http://www.memsic.com/support/documentation/wireless-sensornetworks / category/7-datasheets.html?download=152\%3Atelosb $>$. Acesso em: 31 de agosto de 2012. 
MEMSIC. MICA2 Datasheet. 2012. Disponível em: <http://www.memsic. com/support/documentation/wireless-sensor-networks/category/7datasheets.html?download=147\%3Amica2>. Acesso em: 31 de agosto de 2012 .

MENEZES, A. J.; OORSCHOT, P. C. V.; VANSTONE, S. A. Handbook of applied cryptography. Boca Raton, FL: CRC Press, Inc., 1997.

NANO-RK. FireFly 2.2 Datasheet. 2012. Disponível em: <http://www . nanork . org/projects/nanork/wiki/FireFly > . Acesso em: 31 de agosto de 2012.

NATIONAL INSTRUMENTS. LabVIEW. Austin, TX: National Instruments Corporation, 2012. Disponível em: <http://www.ni.com/labview/>. Acesso em: 31 de agosto de 2012.

NIST. Special Publication SP 800-38A - Recommendations for Block Cipher Modes of Operation, Methods and Techniques. National Institute of Standards and Technology. Gaithersburg, MD, December 2001.

NIST. Special Publication 800-38B Recommendation for Block Cipher Modes of Operation: the CMAC Mode for Authentication. Gaithersburg, MD, May 2005. http://csrc.nist.gov/publications/PubsSPs.html.

NIST. Special Publication 800-38C: Recommendation for Block Cipher Modes of Operation: The CCM Mode for Authentication and Confidentiality. Gaithersburg, MD, Jul. 2007.

NIST. Special Publication 800-38D - Recommendation for Block Cipher Modes of Operation: Galois/Counter Mode (GCM) and GMAC. Gaithersburg, MD, November 2007. http://csrc.nist.gov/publications/nistpubs/800-38D/SP800-38D.pdf.

NSA. Skipjack and KEA Algorithm Specifications, version 2.0. Washington, DC, 1998.

OLIVEIRA, B. T.; MARGI, C. B. WSN-ETESec: Criptografia fim-a-fim em redes de sensores sem fio. In: Anais do XXX Simpósio Brasileiro de Redes de Computadores e Sistemas Distribuídos. Porto Alegre - RS: Sociedade Brasileira de Computação, 2012. p. 930-937.

WSN-ETESec: End-to-End Security Tool for Wireless Sensor Networks.

2012. Disponível em: <http://www.larc.usp.br/ cbmargi/wsnetesec $>$. Acesso em: 31 de agosto de 2012.

OLIVEIRA, L. B. Distribuição de Chaves Criptográficas em Redes de Sensores Sem Fio. Tese (Doutorado) — Universidade Estadual de Campinas, 2009.

OliveirA, L. B.; ARANHA, D. F.; GOUVêA, C. P. L.; SCOTT, M.; CâMARA, D. F.; LóPEZ, J.; DAHAB, R. TinyPBC: Pairings for Authenticated Identity-Based Non-Interactive Key Distribution in Sensor Networks. Computer Communications, 2010. To appear. 
RIVEST, R. L.; SHAMIR, A.; ADLEMAN, L. M. A method for obtaining digital signatures and public-key cryptosystems. Commun. ACM, v. 21, n. 2, p. 120-126, 1978.

ROGAWAY, P. Efficient instantiations of tweakable blockciphers and refinements to modes OCB and PMAC. In: Advances in Cryptology - Asiacrypt'04. Nova Iorque, NY: Springer-Verlag, 2004. (Lecture Notes in Computer Science, v. 3329), p. 16-31. ISBN 3-540-23975-8. http://www.cs.ucdavis.edu/ rogaway/papers/ offsets.pdf.

SAKAI, R.; OHGISHI, K.; KASAHARA, M. Cryptosystems based on pairing. In: Symposium on Cryptography and Information Security (SCIS2000). Okinawa: [s.n.], 2000. p. 26-28.

SANTOS, M. A. S. Análise comparativa de protocolos de segurança para redes de sensores sem fio. Dissertação (Mestrado) - Universidade de São Paulo, São Paulo, SP, 2009.

SANTOS, M. A. S.; MARGI, C. B.; JR., M. A. S.; GEOVANDRO, C. C. F. P.; OLIVEIRA, B. T. de. Implementation of data survival in unattended wireless sensor networks using cryptography. In: LCN 2010: Proceedings of the 35th Annual IEEE International Conference on Local Computer Networks. Washington, DC: IEEE Computer Society, 2010. p. 961-967.

SHAH, R. C.; ROY, S.; JAIN, S.; BRUNETTE, W. Data mules: Modeling a three-tier architecture for sparse sensor networks. In: IEEE Sensor Network Protocols and Applications (SNPA) Workshop. Piscataway, NJ: The Institute of Electrical and Electronics Engineers, 2003. p. 30-41.

SIMPLICIO, M. LetterSoup $C$ version for 8-bit platforms. 2009. Disponível em: <http://www.larc.usp.br/ 〜mjunior/en/downloads/index.html $>$. Acesso em: 31 de agosto de 2012.

- Curupira-2: C version for 8-bit platforms (96-bit keys only). 2009. Disponível em: <http://www.larc.usp.br/ mjunior/en/downloads/index. html >. Acesso em: 31 de agosto de 2012.

SIMPliCiO, M.; BARBUDA, P.; BARRETO, P.; CARVALHO, T.; MARGI, C. The Marvin message authentication code and the LetterSoup authenticated encryption scheme. Security and Communication Networks, v. 2, p. 165-180, 2009.

SIMPliCIO, M.; BARRETO, P.; CARVALHO, T.; MARGI, C.; NASLUND, M. The Curupira-2 block cipher for constrained platforms: Specification and benchmarking. In: Proc. of the 1st International Workshop on Privacy in Location-Based Applications - 13th European Symposium on Research in Computer Security (ESORICS'2008). Tilburg University, The Netherlands: CEUR-WS, 2008. v. 397. http://sunsite.informatik.rwth-aachen.de/Publications/ CEUR-WS/Vol-397/.

SIMPLICIO, M. A. Algoritmos Criptográficos para Redes de Sensores. Dissertação (Mestrado) — Escola Politécnica da Universidade de São Paulo, 2008. 
SIMPliCIO, M. A.; OLIVEIRA, B. T. de; BARRETO, P. S. L. M.; MARGI, C. B.; CARVALHO, T. C. M. B.; NÄSLUND, M. Comparison of authenticatedencryption schemes in wireless sensor networks. In: CHOU, C. T.; PFEIFER, T.; JAYASUMANA, A. P. (Ed.). LCN 2011: Proceedings of the 36th Annual IEEE International Conference on Local Computer Networks. Washington, DC: IEEE Computer Society, 2011. p. 450-457. ISBN 978-1-61284-926-3.

STALLINGS, W. Criptografia e Segurança de Redes: princípios e prática. São Paulo, SP: Pearson Education do Brasil, 2008.

TrueCrypt Foundation. TrueCrypt - Free Open-Source On-The-Fly Disk Encryption Software for Windows 7/Vista/XP, Mac OS X and Linux-Downloads. 2012. http: //www .truecrypt.org/downloads.

UFMG. Salão de Ferramentas do SBRC 2012. Belo Horizonte, MG: Universidade Federal de Minas Gerais - Departamento de Ciência da Computação, 2012. Disponível em: <http://sbrc2012.dcc.ufmg.br/sal\%C3\%A3o-de-ferramentas? $\mathrm{m}=1006>$. Acesso em: 31 de agosto de 2012 .

UNDERWOOD, S. MSPGCC. 2009. http://mspgcc.sourceforge.net/.

XIAO, Y.; SHEN, X.; DU, D. zhu. Wireless Network Security. Dallas, TX: Springer-verlag, 2006.

ZHAO, F.; GUIBAS, L. Wireless sensor networks: an information processing approach. Boston, MA: Elsevier-Morgan Kaufmann, 2004. 


\section{APÊNDICE A - PUBLICAÇÃO CIENTÍFICA E DEMONSTRAÇÃO TÉCNICA DA ARQUITETURA}

O artigo completo derivado da principal contribuição deste trabalho, intitulado "WSN-ETESec: Criptografia Fim-a-Fim em Redes de Sensores Sem Fio" (OLIVEIRA; MARGI, 2012a), foi publicado no Salão de Ferramentas do XXX Simpósio Brasileiro de Redes de Computadores e Sistemas Distribuídos (SBRC 2012), o evento mais importante da área de pesquisa em redes de computadores no Brasil.

Segundo a definição dada no site do evento: "O Salão de Ferramentas do SBRC é um fórum que congrega desenvolvedores e pesquisadores interessados na arquitetura, implementação e avaliação prática de sistemas e ferramentas que contribuem com o avanço do conhecimento da área de redes de computadores e sistemas distribuídos." (UFMG, 2012). Esta trilha do referido simpósio inclui, além da sessão de apresentação oral, uma sessão de demonstrações dos sistemas e ferramentas propostos nos artigos publicados, com o objetivo de promover a discussão em torno dos trabalhos e gerar um melhor feedback aos autores, e para que estes compartilhem suas experiências de desenvolvimento e discutam questões de implantação e uso dos sistemas propostos. 
A demonstração da arquitetura foi realizada a partir do uso de seis dispositivos que seguem o padrão IEEE 802.15.4 (IEEE, 2006), dos quais: quatro são nós sensores, que coletam dados do ambiente para serem enviados para o sorvedouro; um é o nó encaminhador (intermediário), que tem como principal objetivo entregar os dados para o nó sorvedouro, mas também simula um nó comprometido por um adversário, enviando os dados indevidamente para o mesmo; e o último é o sorvedouro, que recebe os dados gerados pelos quatro nós sensores, os processa de acordo com a configuração de segurança e os entrega para o servidor de aplicação. Além dos dispositivos sensores, também foi utilizado um computador pessoal para mostrar os dados em sua tela, tantos os obtidos pelo adversário, quanto os entregues pelo sorvedouro à aplicação.

O objetivo desta demonstração foi apresentar a utilização básica da arquitetura em seus modos de funcionamento. Desta forma, cada um dos nós sensores foi configurado em um dos modos de funcionamento da arquitetura descritos na Seção 5.2. A Figura 21 apresenta o leiaute da demonstração.

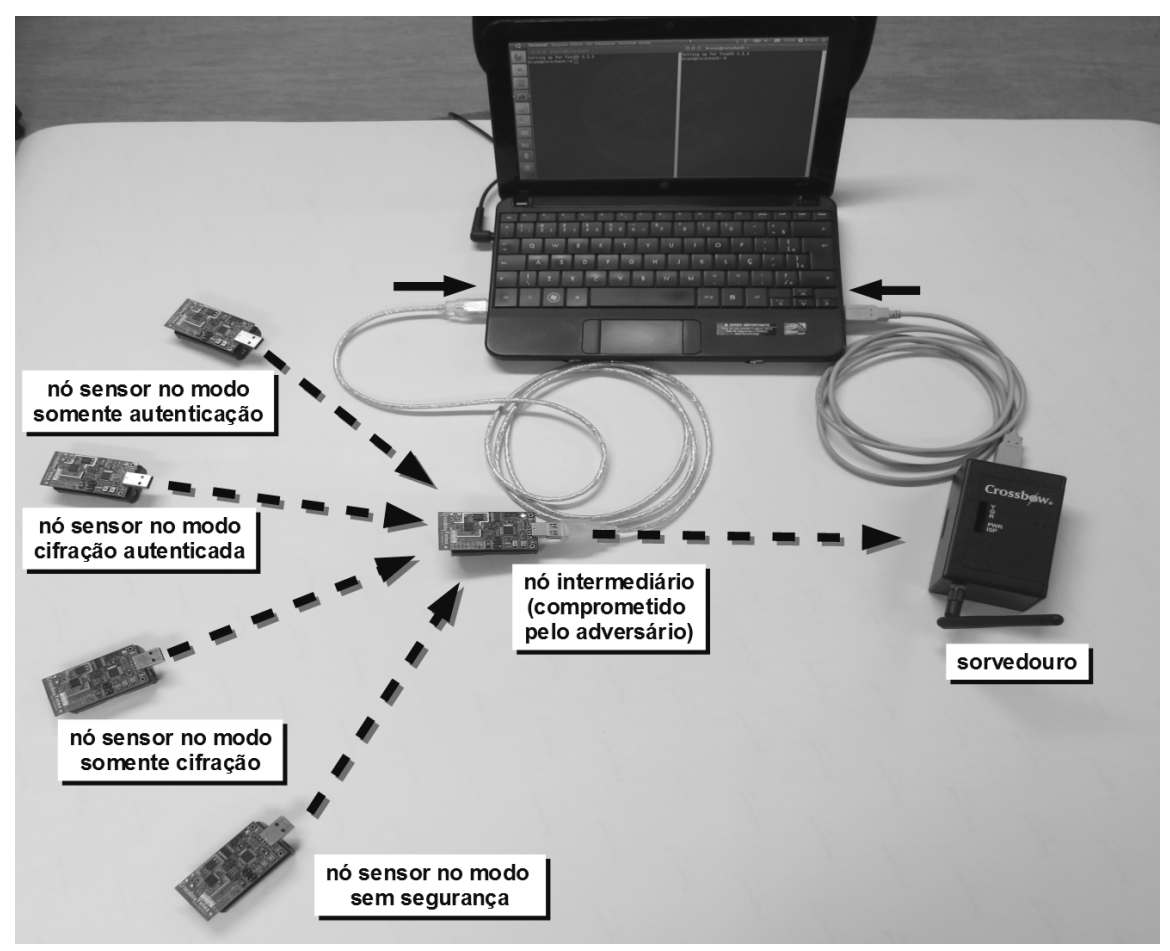

Figura 21: Leiaute da demonstração apresentada no SBRC 2012 